\title{
Oxidative Stress Responsive SERK1 Gene Directs the Progression of Somatic Embryogenesis in Cotton (Gossypium hirsutum L. cv. Coker 310)
}

\author{
Dhananjay K. Pandey, Bhupendra Chaudhary*
}

School of Biotechnology, Gautam Buddha University, Greater Noida, India.

Email: "bhupendrach@gmail.com

Received October $30^{\text {th }}, 2013$; revised December $3^{\text {rd }}$, 2013; accepted December $26^{\text {th }}, 2013$

Copyright (c) 2014 Dhananjay K. Pandey, Bhupendra Chaudhary. This is an open access article distributed under the Creative Commons Attribution License, which permits unrestricted use, distribution, and reproduction in any medium, provided the original work is properly cited. In accordance of the Creative Commons Attribution License all Copyrights (C) 2014 are reserved for SCIRP and the owner of the intellectual property Dhananjay K. Pandey, Bhupendra Chaudhary. All Copyright (C) 2014 are guarded by law and by SCIRP as a guardian.

\begin{abstract}
Somatic embryogenesis (SE) is a prominent mode of regeneration in plants. The acquisition of SE is predominantly invoked by the oxidative stress which plays an important role in signal transduction and cellular redox. Since balanced generation of oxidants is important to cellular differentiation, modulation in cell redox could be responsive to genotypic refinement for SE. To study the dynamics of cellular redox during SE, we conducted comparative expression analyses of cotton (Gossypium hirsutum), using two independently purified near-isogenic lines for the trait of SE. We interrogated expression changes in cell-signaling factor Somatic Embryogenesis Receptor Kinase (SERK) and activity of antioxidant Glutathione in different developmental stages including cotyledonary leaf, calli from different stages of regeneration of fully-regenerating (FR) and non-regenerating (NR) lines of Coker310 cultivar. At evolutionary scale, the cotton SERKs showed high sequence similarity in receptor kinase domain with diverse systems. Exclusively, SERK1 responsible for potential signaling processes during SE revealed significant expression up-regulation in the embryogenic calli of FR line. Similarly, activity of antioxidant glutathione was substantially up-regulated in embryogenic calli of FR line in comparison to its counterpart form. In contrast, calli from early-stages of regeneration of both FR and NR lines had no significant influences on the regulation of SERK and glutathione levels prior to the acquisition of embryogenesis. These results highlight that in vitro purification of FR line in cotton for enhanced regeneration potential (through SE) resulted in signaling and metabolic transformations of the manner in which cellular redox levels have become modulated.
\end{abstract}

\section{KEYWORDS}

Cotton; Somatic Embryogenesis; SERK; Antioxidant

\section{Introduction}

In vitro regeneration is a prominent characteristic of flowering plants observed with wide responses in culture from different vegetative tissues. In an ideal scenario, all somatic cells have a potential to regenerate and give rise to a new plantlet. However, very few cells could be induced with such potential in vitro and the precise mechanisms are largely unknown. Among various plant regeneration systems, somatic embryogenesis (SE) has been reported to be an effective method for plant regene-

${ }^{*}$ Corresponding author.

ration, germplasm conservation and also for genetic transformation experiments [1,2]. During SE, individual somatic cell develops into an embryo and subsequently converted into a complete plantlet providing a model for morphological transformation in developmental studies $[3,4]$. The process of SE involves an induction phase in which somatic cells acquire "embryogenic competence" that may also be considered as intermediate between somatic cell and a pro-embryo [5]. In accordance with zygotic embryogenesis, somatic embryo formation also involved typical globular, heart-shaped, torpedo- and cotyledonary stages of development. The precise me- 
chanism of SE is extremely complex and has been shown to get manipulated mostly with the alterations in micronutrient supplementation in the culture medium. Recently, the importance of micronutrient Boron has been thoroughly reviewed for its possible role in triggering the mechanism of SE [6]. In a recalcitrant plant system, though a prerequisite to the establishment of an efficient and reproducible regeneration system is to understand the molecular mechanism of the SE.

Generally, the intricate process of SE has been induced by abiotic stress conditions in the culture-microenvironment such as wounding of explants through mechanical shearing, minimal to optimal nutrient supplementation, heavy metal ions, osmotic stress and treatment with phytohormones $[7,8]$. The latter has been shown to be the foremost constrain up-regulation of cell-signaling processes in the competent somatic cells [9]. Auxin has been reported to be an important factor involved with the upregulation of cell-signaling and antioxidant molecules during SE [10]. The PIN proteins are known to mediate polar transportation and further establishment of auxin gradient during SE [11]. The spatial expression pattern of the auxin has also been visualised through synthetic auxin-responsive promoter DR5 with a reporter gene confirming the important role of auxin during SE $[12,13]$. For example, comparatively higher endogenous auxin levels have been observed as a distinctive feature of embryogenic calli of carrot [10,14], Pennisetum [15], sugarcane [16] and maize [17]. This observation was further bolstered in cotton by the application of boron-mediated stress conditions that enhanced endogenous auxin level in the somatic cells, resulting into chromatin-remodeling and up-regulation of somatic embryogenesis receptor kinases (SERKs) [6]. The over-expression of SERKs at the cell surface involves in the production of several other molecular signals which act as ligand to the cell surface receptors. These ligands when bind to extracellular domain of SERK mediated by LRR region induce signaling cascade inside the cell. This signal through different sub-steps ultimately targets the nucleus and helps in alteration of the existing gene expression pattern and the cellular or molecular alterations possibly via chromatin remodeling enhance the expression of other somatic embryogenic inducing genes e.g. LEA, LEC, BBM and combined effect of these all compel a somatic cell to embryo transition [18-28]. With this data, it is very clear that SERK-mediated response of varied gene expression pattern may be the key for the somatic cellto-embryo transition of a plant cell.

The Daccus carota SERK (DcSERK) genes were first identified for their over-expression in the embryogenic carrot cell cultures [27]. The elevated expression of SERK in the somatic cells and pro-embryonic mass, and nondetectable expression levels in other vegetative tissues underscore their important role in SE. Based on amino acid sequences, the SERKs have been grouped as the members of a large gene family of receptor-like kinases (RLKs), which contain almost all characteristic features of an ideal receptor [29]. After the first identification of DCSERK, homologous genes have also been reported from Gossypium hirsutum GhSERK1 [30], GhSERK2 [31] and GhSERK3 [32]; A. thaliana (AtSERK1) [33]; Cocos nucifera (CnSERK) [34]; Citrus unshiu (CuSERK1) [35]; Dactylis glomerata (DgSERK) [36]; Daucus carota (DCSERK) [27]; Helianthus annus (HaSERK) [37]; Medicago trancatula (MtSERK) [38]; Oryza sativa (OsSERK) [39]; Solanum tuberosum (StSERK1) [40]; Theobroma cacao (TCSERK) [41]; Triticum aestivum (TaSERK) [42] and Vitis vinifera (VvSERK) [24] with their role in the induction of SE. Sasaki et al. (2007) reported its presence in a green alga Closterium ehrenbergii which suggested the early occurrence of SERK during plant evolution. However, the evolutionary pattern of SERKs is observed to be diverse due to multiple gene duplication events during plant evolution.

In response to oxidative stress conditions, besides the activation of receptor kinase-mediated cell signaling, the up-regulation of certain antioxidant molecules such as glutathione [43,44], superoxide dismutase and catalase [45] suggested for their important role in SE. Exogenous supplementation of culture media with antioxidants such as glutathione in low concentration also promotes SE in Dianthus caryophyllus [46]. However, higher concentration of glutathione further delayed the acquisition of SE [47]. Also, very high activity of glutathione-S-transferase, glutathione peroxidase, catalase, and guaiacol peroxidise during SE has been examined in Eleutherococcus senticosus [48]. Thus the occurrence of SE is directly influenced with varied activity of antioxidant molecules in embryonic callus tissues ranging from gymnosperm to angiosperm [49]. Such current understanding highlighted the role of antioxidant molecules and their genetic regulation during SE $[21,23,50]$. Since, glutathione is widely used as a marker of oxidative stress in plants; therefore, monitoring the activity level of such antioxidants at different stages of in vitro culture may provide us the clues about the potential of somatic cell-to-embryo transition. Moreover, it may be used as a biomarker for the early detection of cell fate in vitro.

The cotton genus (Gossypium) is a very facile system to study the extent of SE where large numbers of experiments have been carried out to test the regeneration potential of different cultivars. However, regeneration of cotton seems to be highly genotype dependent and Coker lines have been reported to be the most amenable to in vitro regeneration [51-57]. The in vitro regeneration in most of the modern cotton cultivars is relatively difficult 
(recalcitrant to regeneration) as cotton varieties are somewhat heterozygous and heterogenous [58]. In our laboratory, two near-isogenic lines for the trait of regeneration have been developed and being maintained over generations [59,60]. These lines have been proved useful particularly in the study of genetics of regeneration trait in cotton and unraveling the intricacies of molecular mechanisms involved during the inception and progression of SE $[52,60]$. Although these studies have provided significant insights into the induced stress conditions in vitro, genetic regulation and signaling in SE [61], there is still much to be learned about acquisition and stabilization of embryogenic potential in cotton. In the present study, the expression and activity analyses of the foremost cell-signaling and antioxidant molecules, respectively were performed to study their relative levels in fully-regenerating and non-regenerating pure lines of cotton. Significant up-regulation of cell-signaling and antioxidant molecules during the acquisition of embryogenic competence warrants them to be potential early biomarkers for somatic cell-to-embryo transition in cotton. Because the pure lines selected for this study represent two near-isogenic lines having contrasting regeneration phenotypes in vitro, we were able to determine the extent of expression changes of signaling and activity of antioxidant molecules during the progression of SE. Thus for the first time, collaborative and balanced contribution of SERK and antioxidant glutathione in the acquisition of SE was identified and could be considered as robust and reproducible beforehand biomarker of embryogenic-potential in cotton.

\section{Materials and Methods}

\subsection{Maintenance of Cotton Germplasm and in Vitro Tissue Culture}

Two near-isogenic lines (FR and NR lines) of cotton (Gossypium hirsutum L. cv. Coker 310) were grown in the cotton green house at Gautam Buddha University, UP at $32^{\circ} \mathrm{C}$ temperature and $16: 8 \mathrm{hrs}$ day/night length. The FR and NR lines were maintained over generations by self-pollination and have also been regularly tested for the purity of fully- and non-regeneration trait in vitro, respectively. The seeds of both FR and NR lines were delinted with sulphuric acid treatment and washed thoroughly with tap water at least for 30 minutes. Delinted seeds were surface sterilized following [62] and germinated on half-strength MS medium [63] (Table 1). The cotyledonary explants with approximate area of $1 / 2 \mathrm{~cm}^{2}$. from 7-day-old seedlings were used for in vitro SE. All inoculations were carried out in a laminar air flow cabinet and the cultures were grown in 9-cm-diameter disposable petri dishes (Tarsons, India). The explants were incubated in controlled environmental conditions at $28^{\circ} \mathrm{C}$ $\pm 1^{\circ} \mathrm{C}, 12: 12 \mathrm{hrs}$ light/dark combination. Composition of different culture media used in the present study is shown in Table 1. Initially these explants were incubated on MST1 medium supplemented with auxin and cytokinin hormonal combination for callus induction. After 30 days of incubation, the first phase white-friable calli were transferred on MSOT2 medium and allowed to grow upto 30 - 40 days. At this stage, the brownish calli were again transferred to MSOT2 medium for a second round of sub-culturing. After two subsequent cycles on MSOT2 medium, only white-granular and yellowish-granular calli were transferred to high nitrate MSOT3 medium and allowed to grow for at least 15 days for the emergence of embryogenic calli. In the present study, all calli from different developmental stages were harvested atleast in three biological replicates.

\subsection{Structural Analyses of SERK Proteins}

The protein sequences of GhSERK1 (Accession no. ADR00582), GhSERK2 (Accession no. AEA76434.1) and GhSERK3 (Accession no. AEG25668) obtained from National Center for Biotechnology Information (NCBI) protein database and converted into graphics format to observe different domains in the entire protein sequence (Figure 1). The sequence analysis of GhSERK1 was performed at the NCBI (http://www.ncbi.nlm.nih.gov/) along with other in silico tools, for example, Simple Modular Architecture Research Tool (SMART;

http://smart.embl-heidelberg.de/) and Pfam

(http://pfam.sanger.ac.uk/), which showed its resemblance with the domains reported earlier in the SERK protein in other species including signal peptide, leucine zipper, leucine rich repeats, Ser-Pro rich region, transmembrane domain, kinase domain and C-terminal region. Further analysis of GhSERK1 with its variants in cotton was performed using EPipe server

(http://www.cbs.dtu.dk/services/EPipe/) to elaborate the functional differences of all variants. The protein sequences of GhSERK1, GhSERK2 and GhSERK3 were directly submitted to the EPipe server platform as query to perform this analysis. Further, 3D structure for GhSERK1 were predicted using Swiss-Model Workspace (http://swissmodel.expasy.org) and PyMOL Molecular graphic system. The predicted model was further validated using Ramachandaran plot analysis.

\subsection{Phylogenetic Analyses of GhSERKs}

Sequences of different SERK protein variants of Triticum aestivum (AEP14551.1), Oryza sativa (AAU88198.1), Daucus carota (AAB61708.1), Cocos nucifera (AAV 
(Gossypium hirsutum L. cv. Coker 310)

Table 1. Composition of the various media used [64].

\begin{tabular}{|c|c|c|c|}
\hline \multicolumn{4}{|c|}{ Name and composition of different culture media } \\
\hline $1 / 2 \mathrm{MS}$ & MST1 & MSOT2 & MSOT3 \\
\hline $\begin{array}{l}\text { MS salts in half-strength }+ \text { B5 } \\
\text { vitamins }(0.5 \mathrm{x})+2 \% \text { Sucrose } \\
\quad+0.7 \% \text { Agar, } \mathrm{pH}-5.80\end{array}$ & $\begin{array}{c}\text { MS salts + B5 vitamins }(1 \mathrm{x})+3 \% \\
\text { Dextrose + 2,4,D }(100 \mu \mathrm{\mu g} / \mathrm{l})+\text { Kinetin } \\
(500 \mu \mathrm{g} / \mathrm{l})+0.2 \% \text { Phytagel, pH-5.80 }\end{array}$ & $\begin{array}{l}\text { MS salts + B5 vitamins }(1 \mathrm{x})+3 \% \\
\text { Dextrose }+0.2 \% \text { Phytagel, } \mathrm{pH}-5.80\end{array}$ & $\begin{array}{l}\text { MS salts + B5 vitamins }(1 \mathrm{x})+3 \% \\
\text { Dextrose + extra } \mathrm{KNO}_{3}(1.9 \mathrm{gm} / \mathrm{l}) \\
\quad+0.2 \% \text { Phytagel, } \mathrm{pH}-5.80\end{array}$ \\
\hline
\end{tabular}

GhSERK1

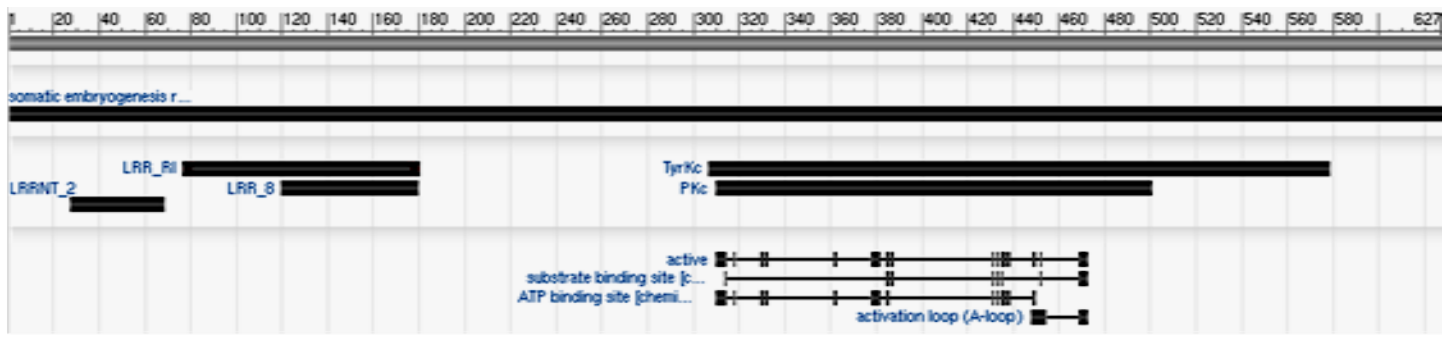

GhSERK2

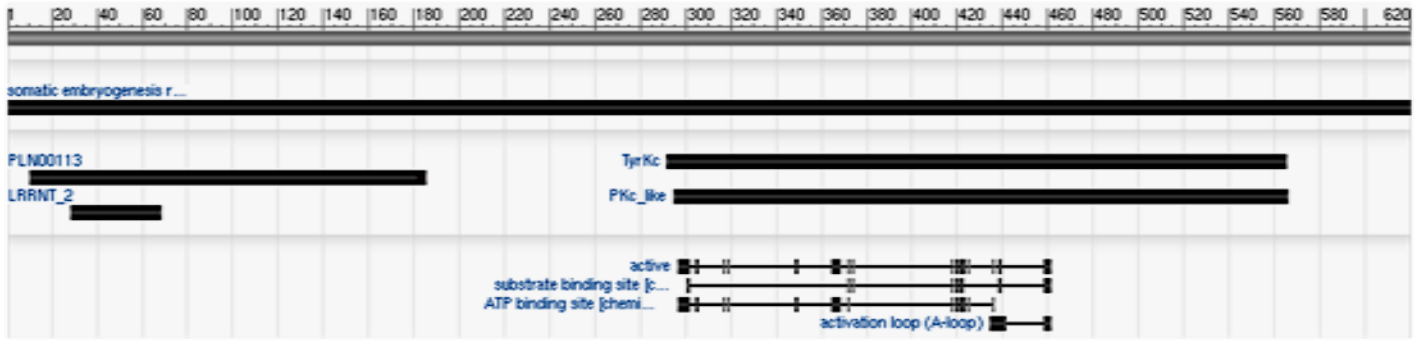

GhSERK3

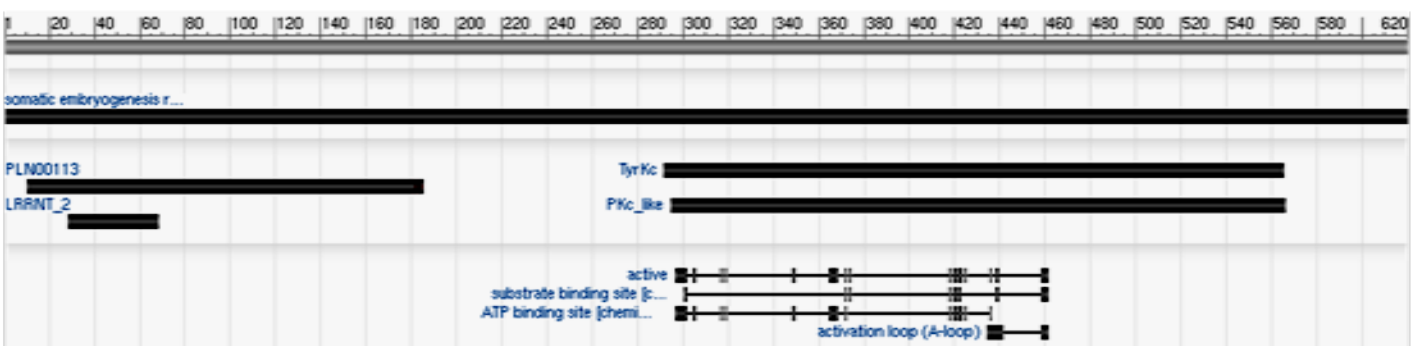

Figure 1. Graphic characterization of different domains in the complete protein sequences of GhSERK1 (627 aa), GhSERK2 (620 aa) and GhSERK3 (620 aa).

58833.2), Solanum tuberosum (ABO14172.1), Arabidopsis thaliana (NP_177328.1), Citrus unshiu (BAD 32780.1), Medicago truncatula (AAN64294.1), Helianthus annuus (AAL93161.1), Theobroma cacao (AAU 03482.1) which have already been reported to be important in SE along with Gossypium hirsutum (ADR00582.1) were obtained from NCBI protein database and used for phylogenetic analysis on Phylogeny.fr online platform (Dereeper A. et al. 2008; http://www.phylogeny.fr/). The sequence alignment was performed using MUSCLE 3.7, followed by the alignment curation through Gblocks 0.91b and PhyML 3.0 aLRT for phylogenetic analysis using Phylogeny.fr online platform.

\subsection{RNA Isolation from Vegetative and Callus Tissues and RT-PCR}

Different vegetative and callus tissues from both FR and
NR lines were used for gene expression analysis. The vegetative and callus tissues included cotyledonary leaf, calli from different stages of regeneration (Figure 2, Table 1). All the harvested samples were frozen in liquid nitrogen, and stored at $-80^{\circ} \mathrm{C}$ before the analysis. RNA was extracted from the stored tissues using RNeasy Plant Mini Kit (Qiagen) in three biological replicates. Isolated RNA samples were analysed for its integrity and purity using Nanodrop (NanoDrop 2000) machine. All samples were treated with DNaseI prior to expression analyses to avoid the contamination of genomic DNA. Isolated RNA after making its dilution of $100 \mathrm{ng} / \mu \mathrm{l}$ was directly used as template for RT-PCR assay for quantitative expression analysis of different genes. The primers of four reference genes GhUBQ14, GhPP2A1, GhGAPDH, GaGAPDH and signaling gene GhSERK1 were designed in Primer Quest, Integrated DNA Tools, Inc. 


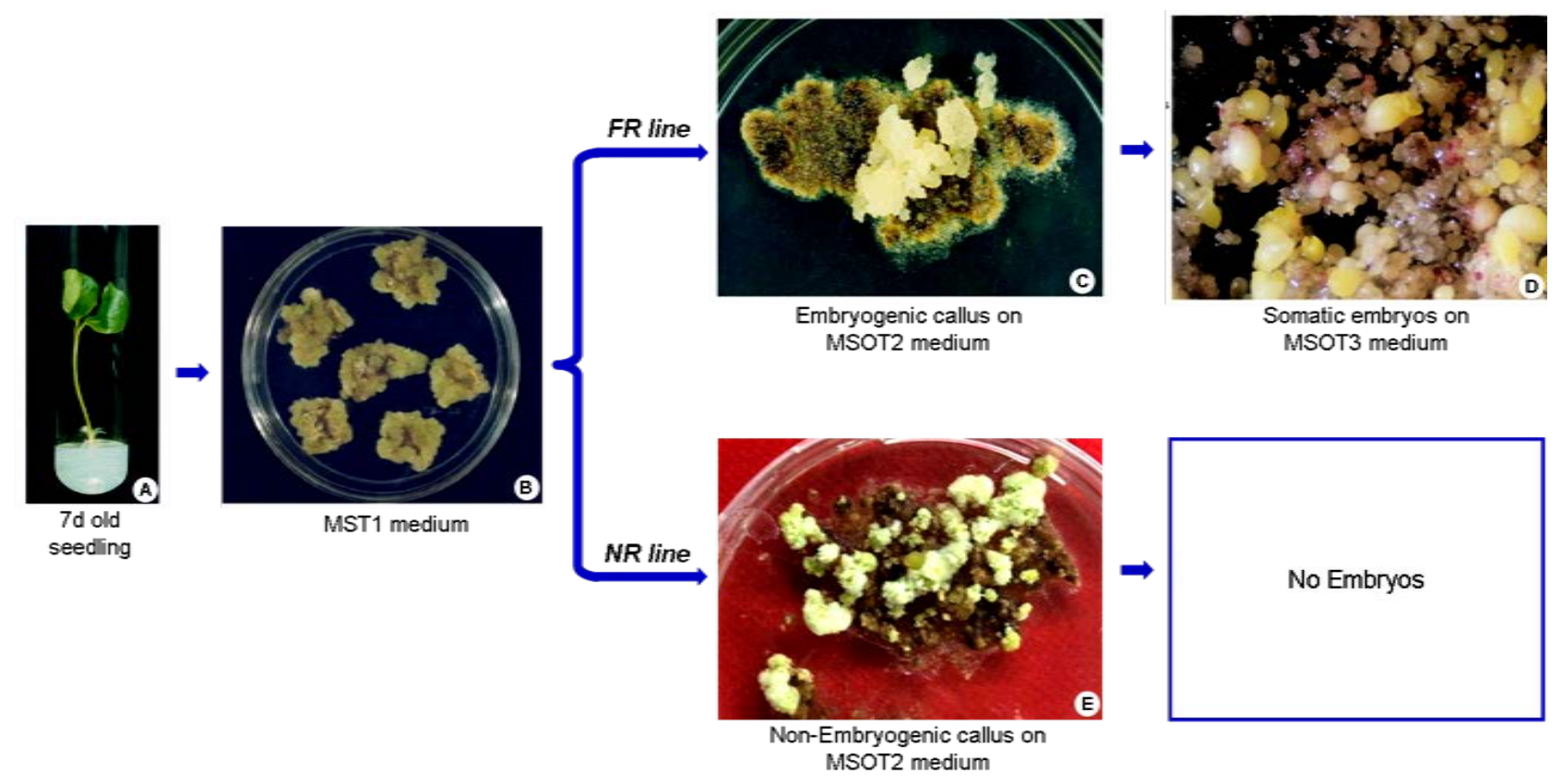

Figure 2. In vitro regeneration of cotton (Gossypium hirsutum L. cv. Coker 310) through somatic embryogenesis. (A) 7 days old seedlings grown on $1 / 2$ MS medium were used for the explant preparation. The cotyledonary leaves were excised into small size explants and inoculated on MST1 medium; (B) The cotyledonary explants with yellowish-friable callus on the edges on MST1 medium after 30 days of incubation; (C) Yellowish-white granular embryogenic callus on MSOT2 medium after second sub-culture on this medium; (D) Embryogenic callus on MSOT3 medium after 15 days of incubation. Embryo development at this stage is normal in FR line in comparison to no embryo formation in NR line; (E) Non-embryogenic whitestony callus formation on MSOT2 medium in NR line.

(http://eu.idtdna.com/scitools/scitools.aspx). To amplify GhSERK1 variant from the pool, primers were designed from hypervariable region of GhSERK1 in order to avoid the probable transcriptional biases during RT-PCR. All designed primers are listed in Table 2.

Quantitative gene expression assay was performed using Stratagene Mx3005P RT-PCR machine (Agilent Technologies) using QuantiFast SYBR Green RT-PCR kit (Qiagen) as per the manufacturer's recommendation. Absolute copy number of cDNA for each gene was calculated by Expression Detection Software (Stratagene) using standard curves. For normalization, the fold difference between the calculated cDNA copy numbers of the analysed genes to that of GhUBQ14 for each biological replicate was calculated and used.

\subsection{Glutathione Assay in Callus Tissues}

Three biological replicates of 7 days old cotyledonary leaf, calli tissue from different stages of regeneration grown on different media (Table 1) were harvested from both FR and NR lines, respectively. A total of $0.5 \mathrm{gm}$ of all the samples was taken in $1.5 \mathrm{ml}$ microcentrifuge tube and Glutathione Detection Kit (Clontech Inc.) was used for this assay as per the manufacturer's instructions with necessary optimization. $100 \mu \mathrm{l}$ ice-cold cell lysis buffer was added in all replicates of various samples. The samples were incubated for $10 \mathrm{~min}$ on ice, and centrifuged at 14,000 rpm for 10 minutes. The supernatant from each sample was collected and transferred to fresh microcentrifuge tube and $2 \mu \mathrm{l}$ of $100 \mathrm{mM}$ Monocholorobimane (MCB) was added. Also, a negative control sample was prepared by adding $2 \mu \mathrm{l}$ of MCB to $100 \mu \mathrm{l}$ of $1 \times$ cell lysis buffer. All samples were again incubated at $37^{\circ} \mathrm{C}$ for the time-intervals varying from 15 minutes to $30 \mathrm{mi}-$ nutes. The fluorescence (emission/excitation) was measured in a plate reader Synergy H1 Hybrid Reader (Biotech Inc.) at 395/480 $\mathrm{nm}$.

\section{Results and Discussion}

\subsection{Somatic Embryogenesis in Cotton}

While the SE has been tested for in vitro regeneration from monocot to dicot plants, very few respond to the varied cultural regimes, particularly cotton, the major fiber crop worldwide. Various in vitro plant regeneration systems have been reported in cotton which includes direct organogenesis from explants such as apical meristem and regeneration from unorganized callus tissues through SE [55,65-68]. Regeneration through SE from unorganized callus tissues has been widely used in culture system for genetic transformation of cotton [69]. As 
Table 2. List of forward and reverse primers used for gene expression analysis through RT-PCR.

\begin{tabular}{ccc}
\hline Name of gene & Primer sequence & Amplicon size \\
\hline \multirow{2}{*}{ GhUBQ14 } & F: 5' CAACGCTCCATCTTGTCCTT 3' & 75 \\
\multirow{2}{*}{ GhPP2A1 } & R: 5'TGATCGTCTTTCCCGAAGC 3' & 100 \\
\multirow{2}{*}{ GhGAPDH } & F: 5' GATCCTTGTGGAGGAGTGGA 3' \\
& R: 5' GCGAAACAGTTCGACGAGAT 3' \\
GaGAPDH & F: 5' TCCGTGTTCCCAACTGTTGATGTCT 3' & 101 \\
GhSERK1 & R: 5'AGATTCCGCCTTGATAGCAGCCTT 3' & 162 \\
& F: 5' TGGGGCTACTCTCAAAGGGTTG 3' & 115 \\
\hline
\end{tabular}

stated previously, regeneration of cotton is highly genotype dependent and greatly varies among elite cultivars. Such large variation in the regeneration potential mainly in the occurrence and magnitude of embryogenesis among different cultivars of G. hirsutum suggests SE in cotton to be a multi-genic trait. Selected cultivars viz. Coker 201, 310, 312 and 315 were observed to be embryogenic, giving rise to healthy and normal somatic embryos. In a large number of studies, some cultural variations have been tested in vitro and callus tissues have been induced to undergo somatic embryogenesis [51,53,55-57]. All these studies have predominantly used Coker lines for regeneration. However, in most of the cases a long period of callus phase is required before embryogenic callus is produced.

In our laboratory, we have purified the cotton cultivar Coker 310 for the trait of regeneration through SE for atleast three subsequent generations. Individual plants of Coker 310 cultivar were tested for their embryogenic potential and the plants showing high frequency embryogenesis were selected and advanced to the next generation. After three subsequent generations of selection, a pure line Coker 310FR (FR stands for fully-regenerating line) was developed for the purity of the trait of regeneration [60] (Figure 2). In parallel, plants showing no embryogenesis trait were also selected and advanced to next three subsequent generations. Thus a pure line Coker 310NR (NR stands for non-regenerating) has also been developed for the purity of non-regeneration trait [59]. The SE experiments were performed in Coker 310FR, primary and secondary calli were raised using cotyledonary explants. Around $45 \%$ of the transferred calli gave rise to different kinds of calli, such as, white-friable, greenish-tough, yellowish-granular and white-granular embryogenic calli (Figure 2). Such embryogenic calli were transferred to MSOT3 medium and $\sim 39 \%$ of the embryogenic calli (around 13\% of the initial explants) gave rise to somatic embryos (Figure 2). However, after following similar culture conditions at initial stages of culture, the NR lines showed whitish-tough and stony callus on MSOT3 medium as in comparison to yello- wish-granular callus in the FR line. Subsequently no induction of embryogenic potential could be observed in the NR calli (Figure 2). Thus both the FR and NR lines are being checked over generations for the trait of full-regeneration and non-regeneration traits and are being maintained as pure lines in the laboratory. The FR and NR lines are the NILs having identical genetic backgrounds diverging only for the trait of SE in vitro. Therefore, such variability in the occurrence and magnitude of SE between FR and NR lines assisted in the formulation of a genetic model to study the molecular mechanism of SE in cotton.

\subsection{Stress-Mediated Cell-Signaling during Embryogenesis}

One of the major concerns in regeneration biology is the identification and characterization of essential molecular components those get manipulated in response to the stress conditions in vitro prior to embryogenesis. Previously, we have reported that the micronutrient boron-mediated stress increased endogenous auxin level in the SE-competent cells [6]. It is thus evident that auxin level is critical in the induction of SE in cotton, which subsequently may influence genetic and cellular transfactors essential for cell-restructuring during SE. Under stress condition, higher auxin level in the cell may further change the transcript profiling of certain signaling genes, known to be responsible for the initiation of cascade of embryogenesis events. It is evident that in response to the enhanced endogenous level of auxin in the cell, the expression of somatic embryo-related factor $(S E R F)$ genes, $\mathrm{Ca}^{2+}$ ion channel-mediated regulatory gene expression and the somatic embryo receptor kinase $(S E R K)$ genes are up-regulated, and are reported earlier to be essential for SE [70]. Since auxin is supplemented in the MST1 medium (Table 1) for the induction of first phase callus in cotton (Figure 2), the latter have attracted more attention as reported for their direct role in the acquisition of SE and studied here to comprehend its implied contribution in the induction of SE. 


\subsubsection{Structural Domains of GhSERK Variants}

All three variants of cotton SERKs i.e. GhERK1 (Accession number ADR00582), GhSERK2 (AEA76434.1) and GhSERK3 (Accession number AEG25668) encode putative SERK-like proteins consisting of 627, 620 and 620 aa, respectively, with a similar amino acid sequence. The GhSERK1 variant showed significant structural variations in the N-terminal region than GhSERK2 and GhSERK3 variants (Figure 1). However, in the ClustalW alignment, the similarity between three cotton SERK proteins and other species SERKs is striking and it is spread all over the sequence, with the notable exception in the $\mathrm{N}$-terminal domain (Figure S1). This may be due in part with differences in the ligand-binding and target domains evolved along with the species lineage.

The sequence analysis of GhSERK variant proteins using bioinformatic tools exhibited all typical features of SERK proteins of other species, such as a signal peptide (SP) domain, a leucine zipper (ZIP) domain, five LRR domains, an SPP motif (which is the hallmark of SERK proteins), a transmembrane domain (TM) and a kinase domain (Figure 3(a)). The amino acid sequence of GhSERK1 protein evidenced a total of 627 amino acids consisting of a SP domain (1-28 aa position) mainly responsible for its precise translocation in the cell, a leucine rich repeat N-terminal (LRRNT) (28 - 68 aa position), a leucine-rich repeats ribonuclease inhibitor (LRR_ RI) (77 - 180 aa positions) and a LRR8 region (120 - 179 aa position). The LRRs are essentially 20-29 residue sequence motifs with canonical signature present in different proteins that participate in protein-protein interaction and cellular localization. A typical 307 to 578 region of amino acid targets Tyrosin kinase catalytic domain (TyrKc) made up of active site, substrate binding site, ATP binding site and also including an activation loop region (a SERK-specific A-loop catalytic domain, spanning residues 450 - 478) was detected in parallel to the 310 to 500 amino acid positions for PKc domain (catalytic domain for protein kinase) (Figure 1). In the A-loop Ser, Thr or Tyr residue reversibly regulate the conformational changes occurred during phosphorylation which activates the kinase domain by allowing ATP and substrate mobility to the active site [71]. In the complete protein sequence, amino acid positions of 314, 385, 387, 431, 433, 435, 452, 469 - 472 were identified as substrate binding sites. Different number and combination of LRR motifs in the extracellular domain of SERK protein might explain the specificity to the ligand binding for cell-signaling in SE [72]. The kinase domain actively participates in the signal transduction pathways transmitting the signals to the target cell-surface through the induction of SE [73]. On contrary to GhSERK1, high structural similarities between GhSERK2 and GhSERK3 amino acid (a)

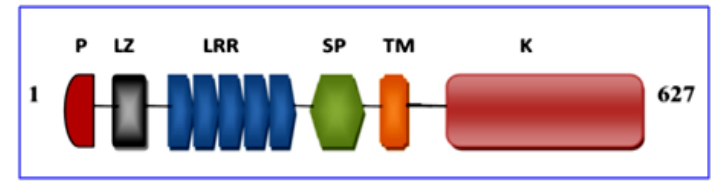

(b)

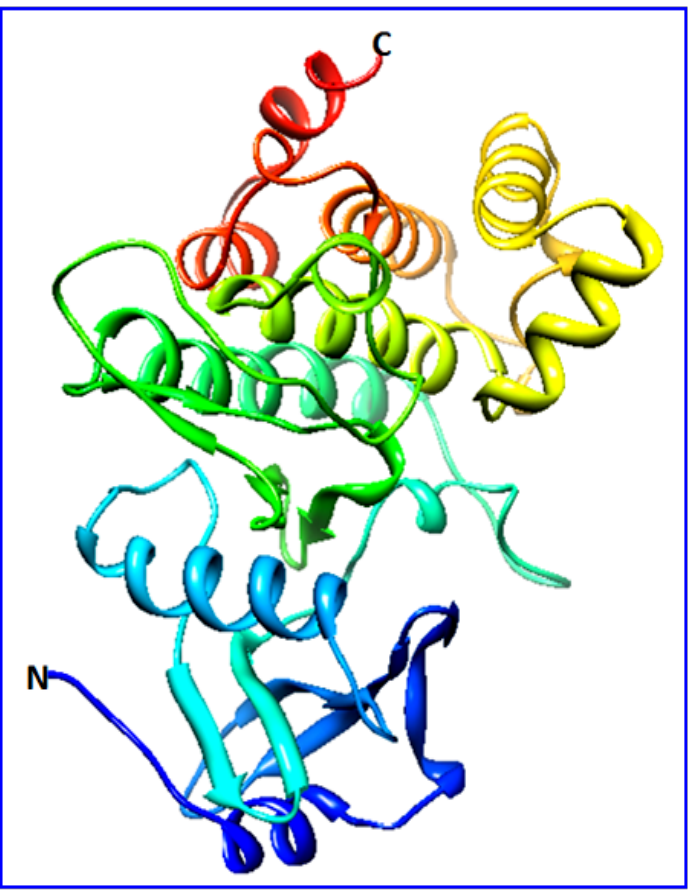

(c)

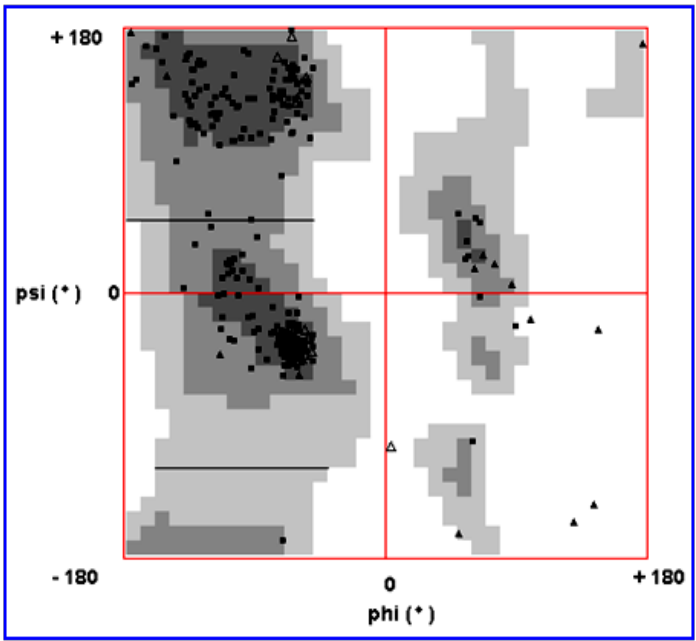

Figure 3. Structural features analysed in the cotton SERK variant (GhSERK1). (a) Schematic representation of GhSERK1 containing a signal peptide (SP) domain, a leucine zipper (ZIP) domain, five LRR domains, an SPP motif (which is the hallmark of SERK proteins), a transmembrane domain (TM) and a kinase domain; (b) Representation of modeled GhSERK1 protein. The $\alpha$-helices and $\beta$ sheets are shown as helices and ribbons, with other regions as loop; (c) Ramachandran plot analysis was used to validate the predicted model. The plot statistics are: 245 $(81.13 \%)$ residues in most favoured regions; 47 (15.56\%) residues in additional allowed regions; $4(1.32 \%)$ generally allowed region and $6(1.99 \%)$ residue in disallowed regions. 
sequences at domain level have been noticed (Figure 1). The SP and the LRR domains extended to 1 - 11 and 11 185 aa positions, respectively. The $29-68$ aa position region represents LRRNT, and 292 - 565 has TyrKc. The 295 - 566 aa position represents the catalytic domain of a protein kinases. The protein kinase domain was relatively smaller in GhSERK1 than other two variants. The 297 461 amino acid sequence harbors the functional components as active sites, ATP binding sites, substrate binding sites and A-loop region (Figure 1). It was also evident that the SP domain and N-terminal domain has maximum diversity; and kinase and LRR regions have maximum similarity on the basis of amino acid sequences. Therefore, it could be hypothesized that at evolutionary basis LRR and kinase domains are more conserved than other regions. Since the role of SERK proteins has been established in the acquisition of SE in different species, it becomes essential to investigate if the differences between GhSERK1 and GhSERK2/GhSERK3 on structural and evolutionary basis have significant role in SE. To further understand the domain organization of GhSERKs, evolutionarily diverged plant species were analyzed for domains' structure. The GhSERK1 amino acid sequence in the predicted 3D structure (Swiss-Model Workspace,

http://swissmodel.expasy.org/) showed highly significant similarity in the PDB database for whichQMEAN ZScore is -0.432 (Figure 3(b)), and was validated using Ramachandran plot (Figure 3(c)). The EPipe server (http://www.cbs.dtu.dk/services/EPipe/) was used to analyse the functional differences in the protein sequences of GhSERK variants in order to relate any specific variant to SE. The results showed significant differences in GhSERK1 from two highly similar GhSERK2 and GhSERK3 variants (Figure S2).

\subsubsection{Conservation of SERKs in Cotton and Other Species}

We compared cotton SERK variants with other SERK genes identified earlier in eudicots Cyclamen persicum (Cp), Solanum tuberosum (St), Glycine max (Gm), Arabidopsis thaliana $(\mathrm{At})$, Citrus unshiui, $(\mathrm{Cu})$, Citrus sinensis (Cs), Helianthus annus (Ha), Daccus carota (Dc), Medicago trancatula (Mt), Ananas comosus (Ac); and the monocots Zea mays (Zm), Triticum aestivum (Ta), Lactuca sativa (Ls), Coffea conephora (Cc), and Oryza sati$v a(O s)$. On the basis of the sequence alignment result, the amino acid sequence of dicot and monocot species showed high homologous regions mainly in the receptor kinase region, as also shown previously [27]. However, maximum differences were observed in their peptide signal domains (Figure S1).

Besides the key role of SERKs in SE, spatial expression was detected in many of all vegetative tissues with high transcript abundant in the reproductive organs highlighting the multi-function of SERK-mediated signaling [74]. Therefore, to understand the precise function of SERK variant particularly in SE at evolutionary scale, SERK variants from different species reported earlier for their exclusive role in SE were multi-aligned, including all three cotton SERK variants. In result, the GhSERK1 showed high similarity with SE-related SERKs of other species (Figure 4), whereas GhSERK2 and GhSERK3 were clustered distantly (data not shown). Therefore, on the evolutionary basis, GhSERK1 is different from GhSERK2 and GhSERK3 and may be presumed of its direct role in SE. This observation further supports the fact that not all SERK variants are involved in the process of SE. The SERK protein from Arabidopsis and Citrus species appeared the most evolutionary related to GhSERK1, which are also close to SERK proteins from Medicago and Helianthus in a distinct branch, to other diocots (Figure 4). However, monocot entries TaSERK1 and OsSERK1 were well-separated in a distinct cluster, which is more distantly related to all dicots including GhSERK1. This data suggest that many SE-related SERKs are evolutionarily conserved among plant species atleast for their functional component. Alignment results also suggested that among peptide signal sequences of CnSERK3, MtSERK3 and OsSERK have significant variation available which may be due to their differential translocation in the cell. However, high sequence similarities were examined in the receptor kinase domains among diverse species. So, are the precise evolutionary changes in SE-related SERK variants species-specific or global? It may be speculated that the SERK-mediated acquisition of SE is mostly based on the structural changes acquired by the selected SERK variants within and across species.

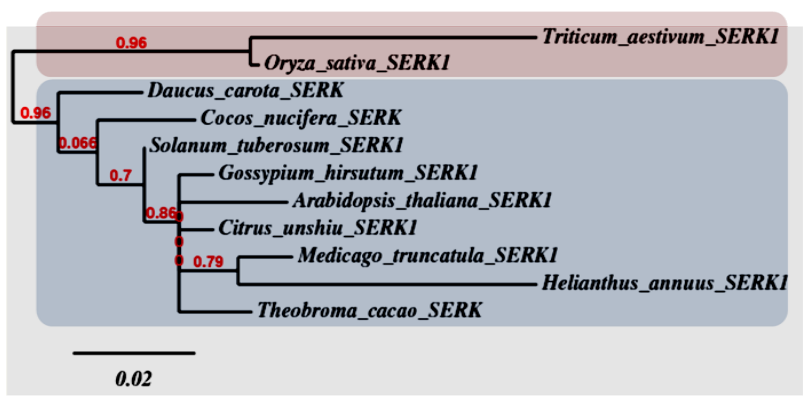

Figure 4. Phylogenetic analysis of GhSERK1 and other homologs reported earlier to have their direct role in SE. Protein alignment was performed using Phylogeny.fr online tool and the maximum likelihood tree was generated. Numbers indicate percent of unit bootstrap analyses. The eudicot SERKs are clustered together (highlighted by blue box); and monocot SERKs in a distinct cluster (highlighted by brown box). 


\subsubsection{Validation of Reference Gene in FR and NR Callus Tissues}

So far most of the studies on gene expression in various vegetative tissues and developmental stages across plant species have been carried out using a single reference gene based on their moderate expression level and stability. In the current study, the expression stability of four well-utilized candidate genes was assessed by qRTPCR using a set of cDNAs of different callus tissues from three developmental culture regimes. These genes included GhUBQ14, GhPP2A1, GhGAPDH and Ga$G A P D H$. The selected genes were chosen very carefully involved in distinct biological processes and metabolic pathways in order to avoid possible errors due to the interaction of co-regulated genes. As mentioned above, the studied developmental stages included 7 days old cotyledonary leaf, early stage callus tissues of both FR and NR lines grown on MST1 and MSOT2 media, and embryogenic callus of FR line (Figure 2). The GAPDH gene was analysed from both diploid (G. arboreum GAPDH: GaGAPDH) and polyploid (G. hirsutum GAPDH: GhGAPDH) cotton species. The selected reference genes were examined for their expression analyses at different developmental stages using specific primers for each gene on the basis of their tentative consensus sequences (Table 2). Primer design and optimization were done by Primer Quest (Integrated DNA Technologies, Inc.) software having PCR amplicon length varying between 70 to 200 bp.

Box plot analysis was performed to study the expression level of all four genes studied in both FR and NR lines (Figure 5). The expression of all four genes varied significantly with the highest expression by the GhGAPDH gene across developmental stages of FR line, whereas GaGAPDH gene expressed the highest in NR lines with mean log values of thresholds $(L t)$ between 3 and 3.1, respectively. The most variable expression ( $L t$ range: $\sim 3$ to 3.2) was recorded in the GhPP2A1 genes (Figure 5), affirming it as the least preferable candidate reference gene in callus tissues' gene expression analysis especially in SE. However, GhUBQ14 was the only candidate gene considered moderately expressed in both FR and NR lines (Figure 5). The GhUBQ14 expression was examined having near median values principally resulted from minimal $L t$ deviations across vegetative and callus tissues of both FR and NR lines. Hence, the GhUBQ14 and GhGAPDH were selected the most two suitable reference genes for the normalization of gene expression in the callus tissues. Further, GeNorm application [75] was used for evaluation of the best reference gene, and in result, the GhUBQ14 was found to be the most stable gene followed by the GaGAPDH gene in both vegetative and callus tissue samples of FR and NR lines. Though all

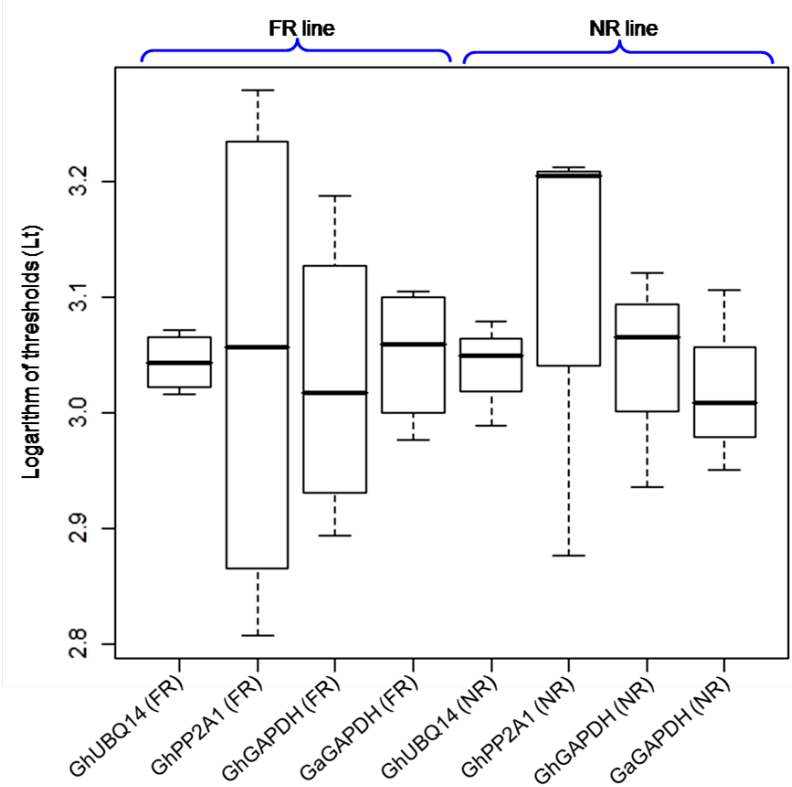

Figure 5. Box-plot analysis of four candidate reference genes in both FR and NR lines showing expression level of different developmental stages of callus tissues. The expression levels (log of threshold values) of each candidate reference gene are shown, median (horizontal lines), $25^{\text {th }}$ to $75^{\text {th }}$ percentile (boxes) and expression ranges (whiskers).

studied genes had previously been shown to be good reference for gene expression analyses across vegetative tissues based on their expression stability [76], but have limited available knowledge on their use as potential candidate reference gene for expression profiling in callus tissues of cotton. This report will be very useful in future studies for selection of a good reference gene for gene expression analysis at least in the cotton callus tissues.

\subsubsection{GhSERK1 is Transcriptionally Up-Regulated in Embryogenic Callus Tissues}

The SERK genes are plant kinases known for their spatial expression mainly in the acquisition of $\mathrm{SE}$ and also in stress responses, for example, ABA treatment [77,78], ethylene production $[79,80]$ and micro-nutrient supplementation [6]. Isolation and characterization of three cotton homoeologous gene encoding GhSERKs with their full-length transcript sequence have been reported previously, exhibiting homology with other species SERKs, for example, five SERK genes from Arabidopsis [33], four genes from Helianthus annus [37], and three genes from Zea mays [81]. Results from the phylogenetic analysis of GhSERK proteins demonstrated very high amino acid similarity of GhSERK1 with SERK proteins from other species characterized earlier to be directly involved in SE, than GhSERK2 and GhSERK3 (Figure 4). We further investigated the role of GhSERK1 in cotton SE by 
analysing its expression levels in different vegetative and callus tissues. The transcript quantity of the target gene GhSERK1 was determined by the qRT-PCR in the same RNA samples used earlier for the selection of reference genes. The relative expression level of the gene of interest was calculated in three sample replicates of different tissues as described before. The GhSERK1 gene expression was normalized by using the best two reference genes that is GhUBQ14 and GaGAPDH (characterized above) because of their stable gene expression levels across callus tissues. Relative to both the reference genes, the mRNA of GhSERK1 was constitutively expressed though at varied levels and greatly dependent on the type of tissue and stages of callus, with very high transcription in the embryogenic callus tissues of FR line (Figure 6(a)). The embryogenic callus tissues are yellowish-granular and get converted into pro-embryos at very high rate when cultured on MSOT3 medium (Figure 2, Table 1). On contrary, low transcript abundance was detected in other vegetative and callus tissues of both FR and NR lines (Figure 6(a)). Normalization of GhSERK1 expression in different tissues using GaGAPDH, mainly in the T3 callus tissues of FR line resulted in a significant increment of its transcription level than those obtained using the most stable reference gene GhUBQ14 (Figure 5). With this data, it is evident that the choice of the reference gene may affect the normalization of GhSERK1 gene expression at least in callus tissues. Thus it becomes essential to choose a suitable reference gene for the normalization of expression data set to lessen the misleading effects, as highlighted previously [82]. To further confirm that the observed phenotypic differences within FR and NR lines are not due to subtle differences in expression pattern of the SERK variants, the GhSERK1 abundance in the embryogenic callus of FR line was also confirmed by the over-expression of GhSERK1-gus translational fusion product under the control of GhSERK1 native promoter, as developed previously [69] (Figure 6(b)). These results explained the significant upregulation of GhSERK1 during the formation of embryogenic calli in FR line, highlighting the enhanced kinase-mediated cellsignaling in the competent somatic cell required for the induction of SE. The up-regulation of GhSERK1 transcript exclusively in the embryogenic calli of FR line suggested for the strong correlation of GhSERK1 with the induction of SE in cotton.

As noted elsewhere, the SERK gene expression is greatly affected by stress conditions and an optimum level of stress acquire an induced shift in the cellular homeostasis required for the induction of embryogenic potential in the somatic cells. The cotyledonary explants of FR line were inoculated on the T1 culture medium supplemented with high levels of exogenous hormones. This may in turn enhance endogenous auxin accumula-

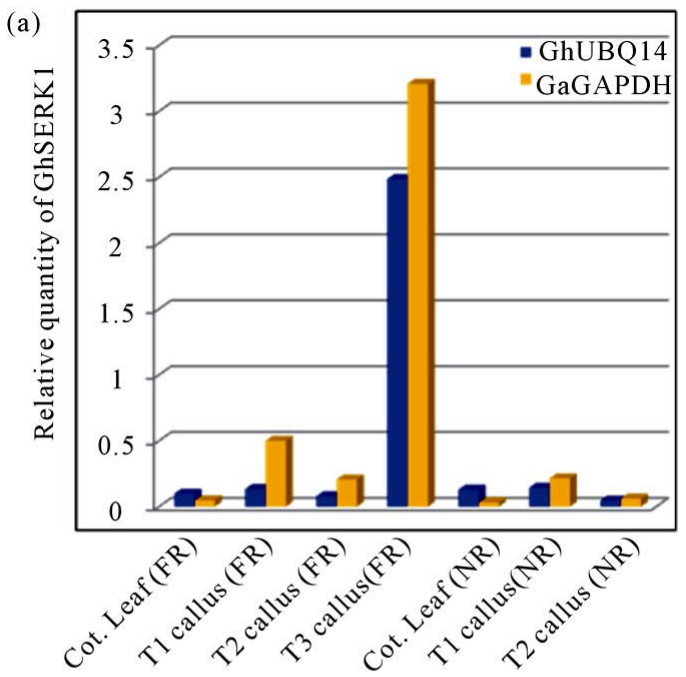

(b)

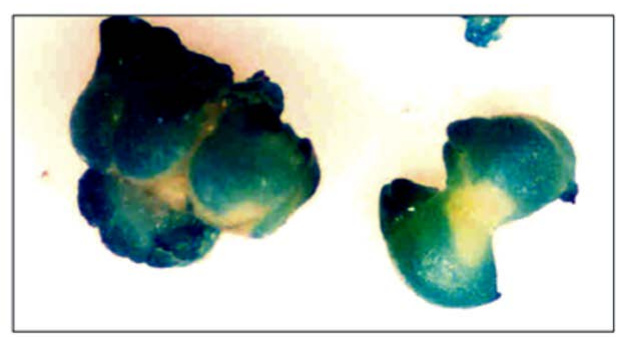

Figure 6. (a) Relative quantification of GhSERK1 transcript using GhUBQ14 and GaGAPDH reference genes as internal controls. Normalized values are plotted from different tissues analysed including cotyledonary leaf, callus tissues of both FR and NR lines grown on MST1 and MSOT2 media; as well as embryogenic callus tissues of FR line grown on MSOT3 medium. The embryogenic callus tissues of NR line could not be produced due to its non-regenerating nature; (b) GUS stained somatic embryos showing over-expression of GhSERK1-gus translational fusion under the control of GhSERK1 promoter.

tion in the somatic cells inducing stress conditions which is essential for switching-on the consequent signaling cascade leading to the induction of embryogenic calli. [70] validated this hypothesis at molecular level showing that auxin had played an important role in reprogramming of gene expression in somatic cell for the induction of embryogenic potential perhaps through SERK-mediated cell signaling. Since the highest expression of GhSERK1 was recorded in the embryogenic callus tissues of FR line, evidenced for the induced stress-mediated up-regulation of cell-signaling leading to a shift in the cellular redox responsible for the morphological transition of somatic cell into an embryonic cell, and is hypothesized in Figure 7. Since in vitro regeneration in elite cotton cultivars is highly genotype dependent, confirming expression of SERK gene(s) at early stages of callus cultures will be very useful in the early detection of somatic to embryonic transition phenomenon. 


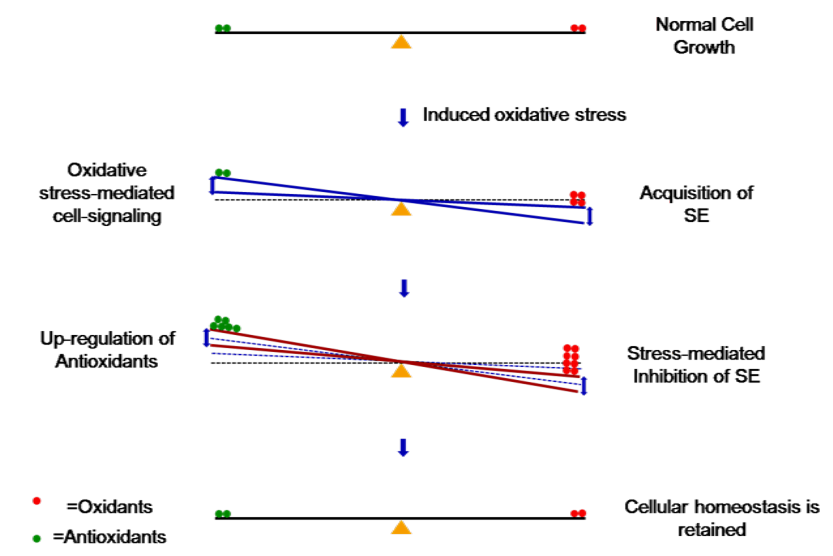

Figure 7. A hypothetical model based on our results showing candidate signaling genes and biological processes statistically over-represented in the embryogenic calli of FR line in comparison to NR line in vitro during the maintenance of cellular redox. In response to the induced stress conditions, certain oxidants are formed inside the cell that in result up-regulated the stress-mediated cell-signaling required for the acquisition of SE. The persistence of induced stress condition beyond a threshold may also compel the somatic cells to cellular damage resulting into radical decrease in the embryogenic potential. Such ROS-mediated cellular damage may be prevented by antioxidant molecules maintaining the cellular redox balance. During the maintenance of this equilibrium in the embryogenic somatic cell, the threshold levels of cell-signaling molecules are suppressed that in result may abolish the embryogenic potential and may not be triggered for SE again in culture.

\subsubsection{Cellular Redox Is Maintained by Up-Regulation of Antioxidant Glutathione in FR-Embryogenic Calli}

As hypothesized, the somatic cells undergo stress conditions induced in the culture medium resulting in the up-regulation of cell-signaling prior to the induction of embryogenic potential (Figure 7). However, persistence of induced stress condition beyond a threshold may compel the somatic cells to cellular damage resulting into radical decrease in the embryogenic potential. Under stress condition, certain reactive oxygen species (ROS) such as free radicals and peroxides are generated by oxidative reactions and other metabolic processes in the cell and could have deleterious effects on the embryogenic transformation. Naturally, cells have evolved with the mechanisms to scavenge excess ROS preventing cellular damage including up-regulation of antioxidant defense mechanisms [83-85].

Glutathione is one of the foremost antioxidant molecules identified for the maintenance of cellular redox levels by preventing ROS-mediated cellular damage $[7,86]$. Using a highly sensitive detection kit, temporal activity of glutathione was estimated in atleast three bio- logical replicates of callus tissues of both FR and NR lines, along with callus tissue of T3 stages from FR line as NR line does not produce embryogenic calli. The antioxidant activity was recorded across tissue samples at different time points of 15, 20, 25 and 30 minutes of incubation with its substrate (Figure 8). The activity level was subsequently normalized using a negative control (NC) in order to reduce the deviations due to background absorption. Relative to NC, glutathione activity was observed at varied levels across tissue types, with very high activity level in the embryogenic calli of FR line (Figure 8). On contrary, low activity was detected in the callus tissues from early stages with insignificant differences between FR and NR lines. The optimal activity of glutathione was recorded after 25 minutes of incubation which sharply declined on 30 minutes of incubation across tissue types (Figure 8).

Previously, it has been proved that the certain enzymes targeting glutathione degradation in the cell are up-regulated during auxin-induced SE in Cichorium $[87,88]$. However, these enzymes have tight regulation of expression mainly through the formation of auxin gradient in the cell during induced stress conditions (Nagata et al. 1994). Cumulatively, these data suggest that embryogenic cells may have a better ability of controlling oxidative stress by regulation of the ROS-scavenging system. The up-regulation of antioxidant glutathione exclusively in embryogenic callus tissues supported the assumption that only the somatic cells undergoing stress condition upto a threshold level are eligible for the acquisition of embryogenic potential. However, as the stress condition

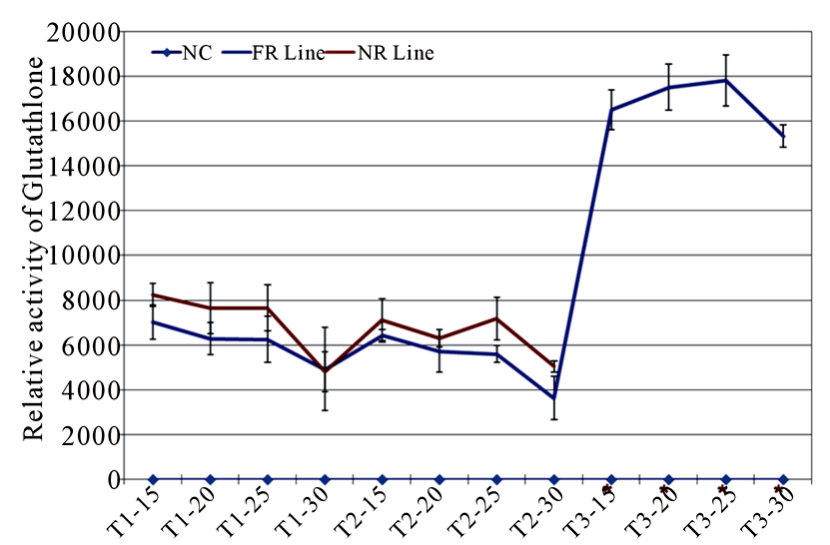

Figure 8. The antioxidant glutathione activity recorded across tissues included cotyledonary leaf, callus tissues of both FR and NR lines grown on MST1 and MSOT2 media; as well as embryogenic callus tissues of FR line grown on MSOT3 medium. The asterisks shown on the $x$-axis represent the non-availability of embryogenic calli from NR line. The glutathione activity was normalized using a negative control (NC) labelled on the $x$-axis across tissue types. All reading were recorded at three time-points of incubation with the substrate and also graphed relative to the NC. 
prevails, the antioxidant level will increase in the cell to maintain the cellular redox balance avoiding toxic effects of the ROS (Figure 7). However, modulation of ROS levels may also be linked to in vitro regeneration and SE as optimal amount of endogenous hydrogen peroxide has been considered as a trigger for signal transduction. But if the ROS level approaches to higher concentrations, the cell switches-on the defence system via over-accumulation of antioxidant molecules to scavenge the ROS [89].

From the aforementioned work on the relationship of hydrogen peroxide levels and SE, it is clear that in response to the increased ROS, up-regulation in the activity of antioxidants will maintain the cellular redox levels through scavenging excess ROS. Hence, it may be assumed that in order to maintain cellular homoeostasis, even the optimal levels of ROS essential in SE will be scavenged. Since the competent somatic cells entail stress-mediated optimal ROS levels for the induction of SE (Figure 7), removal of ROS may also elude the embryogenic potential in vitro. To prove this assumption, the embryogenic calli of FR line were allowed to grow on T3 medium for prolonged period to assess the impact of retained cellular homoeostasis on the embryogenic calli. In result, the embryogenic callus evaded its potential of embryogenesis and the embryogenic yellowishgranular calli turned into non-embryogenic white-friable calli (Figure 9). The latter could be further sub-cultured, but without resuming the embryogenic potential, which may be due to prolonged period of sub-culturing in vitro. This data highlighted the role of up-regulated antioxidant molecules in the competent somatic cell in response to the induced oxidative stress. Also, cell-signaling and antioxidant genes (ROS scavengers) are up-regulated in FR line at embryogenic callus stage when compared to NR line. Thus, embryogenic calli of FR line may experience less oxidative stress than NR line cells at the same developmental stage, suggesting a correlation to the differences in cultural phenotypes. This provokes the speculation that some of the stress-related biological processes and genes that are up-regulated in FR line have achieved this through purification of regeneration trait over generations. Since the regeneration character in cotton is largely dependent on the genotype, the stressmediated shift may subside the fine-tuning of the signaling and antioxidant levels resulting into the recalcitrant germplasm.

\section{Conclusion}

The current study implicates an oxidative stress responsive gene network as being involved in the acquisition of SE in vitro, providing the foundation for genotypic purification of an important fiber-crop plant. We provide evidences here into stress responsive genes and proteins

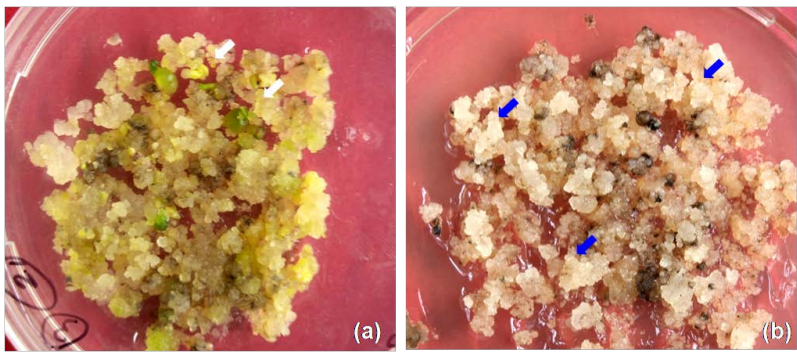

Figure 9. The embryogenic potential is shown in the in vitro cultures of FR line. (a) Yellowish-white granular embryogenic callus on MSOT3 medium after second sub-culture (shown by white arrow); (b) Embryogenic calli of FR line were allowed to grow on MSOT3 medium for prolonged period without any further sub-culture. The yellowish-white granular embryogenic callus get converted into white-friable non-embryogenic callus (shown by blue arrows), showing the loss of embryogenic potential.

that may have been selected during genic-refinement of elite germplasm through the development of in vitro purified fully-regenerating line, starting with initial recalcitrant cultivar. Remarkably, the up-regulated cell-signaling and ROS-scavenging processes are diagnosed as having become enhanced during the induction of embryogenic potential than initial callusing and its prolonged maintenance in culture. The data suggest that in vitro selection pressure led to the recruitment of signaling and ROS scavenging genes considered being concomitant with the purification of fully-regenerating line. The metabolic transformation accompanying in vitro selection provides the means to identify downstream cascade of alteration in gene expression and a beforehand marker of embryogenic potential in cotton. In general, encouraging initial stress-like processes in fully-regenerating line may play a larger role in the enhancement of occurrence and magnitude of embryogenesis through fine-tuning of cell-signaling and stress controlling genes, in conjunction with an increased ability to modulate cellular redox balance in the growing competent cell. An exciting prospect for future work will be to dissect these physiological modifications and their responsible constituent genes in fully-regenerating lines of diverse genomic backgrounds, and to learn the genesis of similarities at genetic or metabolic levels for the altered regulation or function.

\section{Acknowledgments}

We are thankful to Dr. Jitendra S. Rathore, School of Biotechnology for his help in the use of bioinformatic tools, and Pooja Singh \& Prabhat Kumar for skillful technical support. We are also thankful to the Council of Scientific and Industrial Research (CSIR), and the Department of Biotechnology (DBT), Government of India, 
for the financial support to carry out cotton research work in the laboratory.

\section{Declaration}

The authors declare that they have no conflict of interest.

\section{REFERENCES}

[1] E. Firoozabady, M. Heckert and N. Gutterson, "Transformation and Regeneration of Pineapple,” Plant Cell, Tissue and Organ Culture, Vol. 84, No. 1, 2006, pp. 1-16. http://dx.doi.org/10.1007/s11240-005-1371-y

[2] K. K. Kumar, S. Maruthasalam, M. Loganathan, D. Sudhakar and P. Balasubramanian, "An Improved Agrobacterium-Mediated Transformation Protocol for Recalcitrant Elite Indica Rice Cultivars,” Plant Moleculoar Biology Reporter, Vol. 23, No. 1, 2005, pp. 67-73. http://dx.doi.org/10.1007/BF02772648

[3] V. Dodeman, G. Ducreux and M. Kreis, "Zygotic Embryogenesis versus Somatic Embryogenesis," Journal of Experimental Botany, Vol. 48, 1997, pp. 1493-1509.

[4] F. R. Quiroz-Figueroa, R. Rojas-Herrera, R. M. GalazAvolos and V. M. Loyola-Vargas, "Embryo Production through Somatic Embryogenesis can be Used to Study Cell Differentiation in Plants," Plant Cell, Tissue and Organ Culture, Vol. 86, No. 3, 2006, pp. 285-301. http://dx.doi.org/10.1007/s11240-006-9139-6

[5] P. Navasivayam, "Acquisition of Embryogenic Competence during Somatic Embryogenesis,” Plant Cell, Tissue and Organ Culture, Vol. 90, No. 1, 2007, pp. 1-8. http://dx.doi.org/10.1007/s11240-007-9249-9

[6] D. K. Pandey, A. Singh and B. Chaudhary, "Boron-Mediated Plant Somatic Embryogenesis: A Provocative Model,” Journal of Botany, Vol. 2012, No. 2012, Article ID: 375829. http://dx.doi.org/10.1155/2012/375829

[7] O. Faure, W. Dewitte, A. Nougarède and H. Van Onckelen, "Precociously Germinating Somatic Embryos of Vitis vinifera Have Lower ABA and IAA Levels than Their Germinating Zygotic Counterparts,” Physiologia Plantarum, Vol. 102, No. 4, 1998, pp. 591-595. http://dx.doi.org/10.1034/j.1399-3054.1998.1020414.x

[8] M. D. Gaj, "Factors Influencing Somatic Embryogenesis Induction and Plant Regeneration with Particular Reference to Arabidopsis thaliana (L.) Heynh,” Plant Growth Regulation, Vol. 43, No. 1, 2004, pp. 27-47. http://dx.doi.org/10.1023/B:GROW.0000038275.29262.f b

[9] V. M. Jiménez, "Involvement of Plant Hormones and Plant Growth Regulators on in Vitro Somatic Embryogenesis," Plant Growth Regulation, Vol. 47, No. 2-3, 2005, pp. 91-110. http://dx.doi.org/10.1007/s10725-005-3478-x

[10] V. M. Jiménez and F. Bangerth, "Endogenous Hormone Levels in Explants and in Embryogenic and Non-Embryogenic Cultures of Carrot," Physiologia Plantarum, Vol. 111, No. 3, 2001, pp. 389-395.

http://dx.doi.org/10.1034/j.1399-3054.2001.1110317.x
[11] D. Weijers and G. Jürgens, “Auxin and Embryo Axis Formation: The Ends in Sight?” Current Opinion in Plant Biology, Vol. 8, No. 1, 2005, pp. 32-37. http://dx.doi.org/10.1016/j.pbi.2004.11.001

[12] J. Friml, A. Vieten, M. Sauer, D. Weijers, H. Schwartz, T. Hamman, R. Offringa and G. Jürgens, "Efflux-Dependent Auxin Gradients Establish the Apical-Basal Axis of Arabidopsis," Nature, Vol. 426, No. 6963, 2003, pp. 147153.

[13] S. Sabatini, D. Beis, H. Wolkenfelt, J. Murfett, T. Guifoyle, J. Malamy, P. Benfey, O. Leyser, N. Bechtold, P. Weisbeek and B. Scheres, "An Auxin-Dependent Distal Organizer of Pattern and Polarity in the Arabidopsis Root," Cell, Vol. 99, No. 5, 1999, pp. 463-472. http://dx.doi.org/10.1016/S0092-8674(00)81535-4

[14] G. Sasaki, K. Katoh, N. Hirose, H. Suga, K. Kumar, T. Miyata and Z. H. Su, "Multiple Receptor-Like Kinase cDNA from Liverwort Marchantia polymorpha and Two Charophycean Green Alga, Closterium ehrenbergii and Nitella axillaris: Extensive Gene Duplications and Gene Shufflings in the Early Evolution of Streptophytes," Gene, Vol. 401, No. 1-2, 2007, pp. 135-144.

http://dx.doi.org/10.1016/j.gene.2007.07.009

[15] K. Rajasekaran, M. B. Hein and I. K. Vasil, "Endogenous Abscisic Acid and indole-3-Acetic Acid and Somatic Embryogenesis in Cultured Leaf Explants of Pennisetum purpureum Schum: Effects in Vivo and in Vitro of Glyphosate, Fluridone, and Paclobutrazol," Plant Physiology, Vol. 84, No. 1, 1987, pp. 47-51.

http://dx.doi.org/10.1104/pp.84.1.47

[16] E. Guiderdoni, B. Mérot, T. Eksomtramage, F. Paulet, P. Feldmann and J. C. Glaszmann, "Somatic Embryogenesis in Sugarcane (Saccharum Species),” In: Y. P. S. Bajaj, Ed., Somatic Embryogenesis and Synthetic Seed II, Vol. 31, Springer, Berlin, 1995, pp. 92-113. http://dx.doi.org/10.1007/978-3-642-78643-3_9

[17] V. M. Jimenez and F. Bangerth, "Hormonal Status of Maize Initial Explants and of the Embryogenic and NonEmbryogenic Callus Cultures Derived from Them as Related to Morphogenesis in Vitro," Plant Science, Vol. 160, No. 2, 2001, pp. 247-257. http://dx.doi.org/10.1016/S0168-9452(00)00382-4

[18] C. Albrecht, E. Russinova, B. Kemmerling, M. Kwaaitaal and S. de Vries, "Arabidopsis Somatic Embryogenesis Receptor Kinase Protein Serves Brassinosteroid-Dependent and Independent Signalling Pathway," Plant Physiology, Vol. 148, No. 1, 2008, pp. 611-619.

http://dx.doi.org/10.1104/pp.108.123216

[19] S. Braybrook, S. Stone, S. Park, A. Bui, B. Le, R. Fischer, R. Goldberg and J. Harada, "Genes Directly Regulated by LEAFY COTYLEDON2 Provide Insight into the Control of Embryo Maturation and Somatic Embryogenesis," Proceedings of the Natinal Academy of Sciences of the United States of America, Vol. 103, No. 9, 2006, pp. 3468-3473. http://dx.doi.org/10.1073/pnas.0511331103

[20] S. Casson, M. Spencer, K. Walker and K. Lindsey, "Laser Capture Microdissection for the Analysis of Gene Expression during Embryogenesis of Arabidopsis," Plant Journal, Vol. 42, No. 1, 2005, pp. 111-123. 
http://dx.doi.org/10.1111/j.1365-313X.2005.02355.x

[21] A. Chugh and P. Khurana, "Gene Expression during Somatic Embryogenesis-Recent Advances," Current Science, Vol. 83, No. 6, 2002, pp. 715-730.

[22] I. Heidmann, J. Lambalk, R. Joosen, G. Angenent, J. Custers and K. Boutilier, "Expression of BABY BOOM Induces Somatic Embryogenesis in Tobacco," International Conference Haploids in Higher Plants III, Vienna, Vol. 52, 2006, pp. 12-15.

[23] M. Ikeda, M. Umehara and H. Kamada, "EmbryogenesisRelated Genes; Its Expression and Roles during Somatic and Zygotic Embryogenesis in Carrot and Arabidopsis,” Plant Biotechnology, Vol. 23, No. 2, 2006, pp. 153-161. http://dx.doi.org/10.5511/plantbiotechnology.23.153

[24] P. Maillot, S. Lebel, P. Schellenbaum, A. Jacques and B. Walter, "Differential Regulation of SERK, LEC1-Like and Pathogenesis-Related Genes during Indirect Secondary Somatic Embryogenesis in Grapevine," Plant Physiology and Biochemistry, Vol. 47, No. 8, 2009, pp. 743752. http://dx.doi.org/10.1016/j.plaphy.2009.03.016

[25] K. E. Nolan, S. Kurdyukov and R. J. Rose, "Expression of the SOMATIC EMBRYOGENESIS RECEPTOR-LIKE KINASE1 (SERK1) Gene Is Associated with Developmental Change in the Life Cycle of the Model Legume Medicago truncatula," Journal of Experimental Botany, Vol. 60, No. 6, 2009, pp. 1759-1771. http://dx.doi.org/10.1093/jxb/erp046

[26] P. Passarinho, T. Ketelaar, M. Xing, J. Van Arkel, C. Maliepaard, M. Hendriks, R. Joosen, M. Lammers, L. Herdies, B. Boer, L. Van Der Geest and K. Boutilier, "BABY BOOM Target Genes Provide Diverse Entry Points into Cell Proliferation and Cell Growth Pathways," Plant Molecular Biology, Vol. 68, No. 3, 2008, pp. 225237. http://dx.doi.org/10.1007/s11103-008-9364-y

[27] E. Schmidt, F. Guzzo, M. Toonen and S. De Vries, “A Leucine-Rich Repeat Containing Receptor-Like Kinase Marks Somatic Plant Cells Competent to Form Embryos,” Development, Vol. 124, No. 10, 1997, pp. 2049-2062.

[28] Y. Zhenga, N. Renb, H. Wanga, A. J. Strombergb and S. E. Perrya, "Global Identification of Targets of the Arabidopsis MADS Domain Protein AGAMOUS-Like15,” The Plant Cell, Vol. 21, No. 9, 2009, pp. 2563-2577. http://dx.doi.org/10.1105/tpc.109.068890

[29] P. Maillot, B. Walter and P. Schellenbaum, "Somatic Embryogeneisis Recepter like Kinases Are Related to Embryogenesis and Other Developmental and Defence Pathways,” In: A. Kumar and S. K. Sopory, Eds., Recent Advances in Plant Biotechnology and Its Applications, I.K. Publication House, 2008, pp. 154-172.

[30] S. D. Guo, Y.-L. Shi and R. Zhang, "Cloning and Characterization of a Cotton SERK Gene Related to the Development of the Anther in Gossypium hirsutum," The Chinese Academy of Agricultural Sciences, Biotechnology Research Institute, 12 Zhongguancun Nandajie, Beijing (Web Report), 2010.

[31] Y. Zhang, Z. Liu and J. Hua, "Cloning and Characterization of a Cotton SERK-Like Gene,” Department of Plant Genetics \& Breeding, China Agricultural University: De- partment of Plant Genetics \& Breeding, China Agricultural University, Beijing, 2011.

[32] S. D. Guo, Y. L. Shi and R. Zhang, "Cloning and Characterization of a Cotton SERK Gene," Chinese Academy of Agricultural Sciences, Biotechnology Research Institute: The Chinese Academy of Agricultural Sciences, Biotechnology Research Institute, Beijing, 2011.

[33] V. Hecht, J. Vielle-Calzada, M. Hartog, E. Schmidt, K. Boutilier, U. Grossniklaus and S. De Vries, "The Arabidopsis Somatic Embryogenesis Receptor Kinase1 Gene Is Expressed in Developing Ovules and Embryos and Enhanses Embryogenic Competence in Culture,” Plant Physiology, Vol. 127, No. 3, 2001, pp. 803-816. http://dx.doi.org/10.1104/pp.010324

[34] M. Perez-Nunez, R. Souza, L. Seaenz, J. Chan, J. ZunigaAguilar and C. Oropeza, "Detection of a SERK-Like Gene in Coconut and Analysis of Its Expression during the Formation of Embryogenic Callus and Somatic Embryos," Plant Cell Reports, Vol. 28, No. 1, 2009, pp. 11-19. http://dx.doi.org/10.1007/s00299-008-0616-8

[35] T. Shimada, T. Hirabayashi, H. Fujii, M. Kita and M. Omura, "Isolation and Characterization of the Somatic Embryogenesis Receptor-Like Kinase Gene Homologue (CitSERK) from Cirus unshiu Marc.,” Scientia Horticulturae, Vol. 103, No. 2, 2005, pp. 233-238. http://dx.doi.org/10.1016/j.scienta.2004.07.005

[36] M. Somleva, E. Schmidt and S. De Vries, "Embryogenic Cells in Dactylis glomerata L. (Poaceae) Explants Identified by Cell Tracking and by SERK Expression,” Plant Cell Reports, Vol. 19, No. 7, 2000, pp. 718-726. http://dx.doi.org/10.1007/s002999900169

[37] C. Thomas, D. Meyer, C. Himber and A. Steinmetz, "Spatial Expression of a Sunflower SERK Gene during Induction of Somatic Embryogenesis and Shoot Organogenesis," Plant Physiology and Biochemistry, Vol. 42, No. 1, 2004, pp. 35-42. http://dx.doi.org/10.1016/j.plaphy.2003.10.008

[38] K. Nolan, R. R. Irwanto and R. J. Rose, “Auxin Up-Regulates MtSERK1 Expression in Both Medicago truncatula Root-Forming and Embryogenic Cultures,” Plant Physiology, Vol. 133, No. 1, 2003, pp. 218-230. http://dx.doi.org/10.1104/pp.103.020917

[39] H. Hu, L. Xiong and Y. Yang, "Rice SERK1 Gene Positively Regulates Somatic Embryogenesis of Cultured Cell and Host Defense Response against Fungal Infection,” Planta, Vol. 222, No. 1, 2005, pp. 107-117. http://dx.doi.org/10.1007/s00425-005-1534-4

[40] S. K. Sharma, S. Millam, I. Hein and G. J. Bryan, “Cloning and Molecular Characterisation of a Potato SERK Gene Transcriptionally Induced during Initiation of Somatic Embryogenesis,” Planta, Vol. 228, No. 2, 2008, pp. 319-330. http://dx.doi.org/10.1007/s00425-008-0739-8

[41] M. Santos, E. Romano, K. Yotoko, M. Tinoco, B. Dias and F. Argao, "Characterisation of the Cacao Somatic Embryogenesis Receptor-Like Kinase Gene Expressed during Somatic Embryogenesis,” Plant Science, Vol. 168, No. 3, 2005, pp. 723-729.

http://dx.doi.org/10.1016/j.plantsci.2004.10.004 
[42] B. Singla, J. P. Khurana and P. Khurana, "Characterization of Three Somatic Embryogenesis Receptor Kinase Genes from Wheat, Triticum aestivum," Plant Cell Reports, Vol. 27, No. 5, 2008, pp. 833-843. http://dx.doi.org/10.1007/s00299-008-0505-1

[43] M. Belmonte, C. Stasolla, N. Loukanina, E. Yeung and T. Thorpe, "Glutathione Modulation of Purine Metabolism in Cultured White Spruce Embryogenic Tissue," Plant Science, Vol. 165, No. 6, 2003, pp. 1377-1385. http://dx.doi.org/10.1016/j.plantsci.2003.08.002

[44] M. J. Elmore, A. J. Lamb, G. Y. Ritchie, R. M. Douglas, A. Munro, A. Gajewska and I. R. Booth, "Activation Potassium Efflux from Escherichia coli by Glutathione Metabolites,” Molecular Microbiology, Vol. 4, No. 3, 1990, pp. 405-412.

http://dx.doi.org/10.1111/j.1365-2958.1990.tb00607.x

[45] T. Isah and A. Mujib, "Studies on Antioxidant Enzymes Activity during in Vitro Morphogenesis of Caladium bicolor Linn," International Journal of Modern Cellular and Molecular Biology, Vol. 1, No. 1, 2012, pp. 1-9.

[46] M. Agrawal and S. Purohit, "Changes in Antioxidant Enzymes Activity during in Vitro Morphogenesis of Carnation and the Effect of Antioxidants on Plant Regeneration," World Journal of Science and Technology, Vol. 2, No. 7, 2012, pp. 87-92.

[47] M. Belmonte, C. Stasolla, R. Katahira, N. Loukanina, E. C. Yeung and T. A. Thorpe, "Glutathione Induced Growth of Embryogenic Tissue of White Spruce Correlates with Changes in Pyrimidine Nucleotide Metabolism," Plant Science, Vol. 168, No. 3, 2005, pp. 803-812. http://dx.doi.org/10.1016/j.plantsci.2004.10.013

[48] A. M. Shohael, M. Ali, E. J. Hahn and K. Y. Paek, "Glutathione Metabolism and Antioxidant Responses during Eleutherococcus senticosus Somatic Embryo Development in a Bioreactor," Plant Cell, Tissue and Organ Culture, Vol. 89, No. 2-3, 2007, pp. 121-129. http://dx.doi.org/10.1007/s11240-007-9220-9

[49] M. Wiweger, I. Farbos, M. Ingouff, U. Lagercrantz and V. S. Arnold, "Expression of Chia4-Pa Chitinase Genes during Somatic and Zygotic Embryo Development in Norway Spruce (Picea abies): Similarities and Differences between Gymnosperm and Angiosperm Class IV Chitinases,” Journal of Experimental Botany, Vol. 54, No. 393, 2003, pp. 2691-2699. http://dx.doi.org/10.1093/jxb/erg299

[50] R. Rose and K. Nolan, "Genetic Regulation of Somatic Embryogenesis with Particular Reference to Arabidopsis Thaliana and Medicago truncatula," In Vitro Cellular and Developmental Biology Plants, Vol. 42, No. 6, 2006, pp. 473-481.

[51] Z. Chen, S. Li and N. Trolinder, "Some Characteristics of Somatic Embryogenesis and Plant Regeneration in Cotton Cell Suspension Culture," Scientia Agricultura Sinica, Vol. 20, No. 5, 1987, pp. 6-11.

[52] N. Gawel, A. Rao and C. Robacker, "Somatic Embryogenesis from Leaf and Petiole Callus Cultures of Gossypium hirsutum L.," Plant Cell Reports, Vol. 5, No. 6, 1986, pp. 457-459.

\section{http://dx.doi.org/10.1007/BF00269641}

[53] T. Kolganova, D. Srivastava and V. Mett, "Callusogenesis and Regeneration of Cotton (Gossypium hirsutum L.) cv. 108-F,” Soviet Plant Physiology, Vol. 39, 1992, pp. 232-236.

[54] R. Shoemaker, I. Couche and D. Galbraith, "Characterization of Somatic Embryogenesis and Plant Regeneration in Cotton (Gossypium hirsutum L.),” Plant Cell Reports, Vol. 5, No. 3, 1986, pp. 178-181.

http://dx.doi.org/10.1007/BF00269112

[55] N. Trolinder and J. Goodin, "Somatic Embryogenesis and Plant Regeneration in Cotton (Gossypium hirsutum L.)," Plant Cell Reports, Vol. 6, No. 3, 1987, pp. 231-234. http://dx.doi.org/10.1007/BF00268487

[56] K. Voo, C. Rugh and J. Kamalay, "Indirect Somatic Embryogenesis and Plantlet Recovery from Cotton (Gossypium hirsutum L.)," In Vitro Cellular \& Developmental Biology-Plant, Vol. 27, No. 3, 1991, pp. 117-124.

http://dx.doi.org/10.1007/BF02632194

[57] D. Zhang and Z. Wang, "Tissue Culture and Embryogenesis of Gossypium hirsutum L.," Acta Botanica Sinica, Vol. 31, 1989, pp. 161-163.

[58] J. M. Poehlman, “Breeding Filed Crops,” The AVI Publishing Co. Inc., Westport, 1979.

[59] B. Chaudhary, "Development of Non-Regenerating Line in Cotton through in Vitro Purification," Gautam Buddha University, Gr. Noida UP (Unpublished Data), 2013.

[60] S. Kumar, P. Sharma and D. Pental, “A Genetic Approach to in Vitro Regeneration of Non-Regenerating Cotton (Gossypium hirsutum L.) Cultivars,” Plant Cell Reports, Vol. 18, No. 1-2, 1998, pp. 59-63. http://dx.doi.org/10.1007/s002990050532

[61] O. Karami and A. Saidi, "The Molecular Basis for Stress Induced Acquisition of Somatic Embryigenesis," Molecular Biology Reports, Vol. 37, No. 5, 2010, pp. 24932507. http://dx.doi.org/10.1007/s11033-009-9764-3

[62] J. Hemphill, C. Maier and K. D. Chapman, "Rapid in Vitro Plant Regeneration of Cotton (Gossypium hirsutum L.)," Plant Cell Reports, Vol. 17, No. 4, 1998, pp. 273278. http://dx.doi.org/10.1007/s002990050391

[63] T. Murashige and F. Skoog, "A Revised Medium for Rapid Growth and Bioassays with Tobacco Tissue Cultures," Physiologia Plantarum, Vol. 15, No. 3, 1962, pp. 473497. http://dx.doi.org/10.1111/j.1399-3054.1962.tb08052.x

[64] B. Chaudhary, S. Kumar, K. V. S. K. Prasad, G. S. Oinam, P. K. Burma and D. Pental, "Slow Desiccation Leads to High-Frequency Shoot Recovery from Transformed Somatic Embryos of Cotton (Gossypium hirsutum L. cv. Coker 310 FR)," Plant Cell Reports, Vol. 21, No. 10, 2003, pp. 955-960. http://dx.doi.org/10.1007/s00299-003-0613-x

[65] G. Davidonis and R. Hamilton, "Plant Regeneration from Callus Tissue of Gossypium hirsutum L.,” Plant Science Letters, Vol. 32, No. 1-2, 1983, pp. 89-93. http://dx.doi.org/10.1016/0304-4211(83)90102-5

[66] J. Gould, S. Banister, O. Hasegawa, M. Fahima and R. 
Smith, "Regeneration of Gossypium hirsutum and G. barbadense from Shoot Apex Tissues for Transformation," Plant Cell Reports, Vol. 10, No. 1, 1991, pp. 12-16. http://dx.doi.org/10.1007/BF00233024

[67] M. Peetrs, K. Willems and R. Swennen, "Protoplast to Plant Regeneration in Cotton Tissue Cultures,” Physiologia Plantarum, Vol. 15, 1994, pp. 473-497.

[68] H. Price and R. Smith, "Somatic Embryogenesis in Suspension Cultures of Gossypium klotzschiaanum Anderss," Planta, Vol. 145, No. 3, 1979, pp. 305-307. http://dx.doi.org/10.1007/BF00454456

[69] B. Chaudhary, "Development of Transgenics in Cotton (Gossypium hirsutum L. cv. Coker 310FR) for Insect Resistacne and Marker Gene Removal,” Ph.D. Thesis, in Genetics. Ph.D. University of Delhi South Campus, New Delhi, 2006.

[70] T. Takeda, H. Inose and H. Matsuoka, "Stimulation of Somatic Embryogenesis in Carrot Cells by the Addition of Calcium,” Biochemical Engineering Journal, Vol. 14, No. 2, 2003, pp. 143-148. http://dx.doi.org/10.1016/S1369-703X(02)00186-9

[71] X. Huang, M. Begley, K. Morgenstern, Y. Gu, P. Rose, H. Zhao and X. Zhu, "Crystal Structure of an Inactive Akt2 Kinase Domain,” Structure, Vol. 11, No. 1, 2003, pp. 2130. http://dx.doi.org/10.1016/S0969-2126(02)00937-1

[72] A. Dievart and S. Clark, "Using Mutant Alleles to Determine the Structure and Function of Leucine-Rich Repeat Receptor-Like Kinase,” Currunt Opinion in Plant Biology, Vol. 6, No. 5, 2003, pp. 507-516. http://dx.doi.org/10.1016/S1369-5266(03)00089-X

[73] A. Marchler-Bauer, C. Zheng, F. Chitsaz, M. K. Derbyshire, L. Y. Geer, R. C. Geer, N. R. Gonzales, M. Gwadz, D. I. Hurwitz, C. J. Lanczycki, F. Lu, S. Lu, G. H. Marchler, J. S. Song, N. Thanki, R. A. Yamashita, D. Zhang and S. H. Bryant, "CDD: Conserved Domains and Protein Three-Dimensional Structure,” Nucleic Acids Research, Vol. 41, No. D1, 2013, pp. 348-352. http://dx.doi.org/10.1093/nar/gks1243

[74] Y.-L. Shi, R. Zhang, X.-P. Wu, Z.-G. Meng and S.-D. Guo, "Cloning and Characterization of a Somatic Embryogenesis Receptor-Like Kinase Gene in Cotton (Gossypium hirsutum)," Journal of Integrative Agriculture, Vol. 11, No. 6, 2012, pp. 898-909. http://dx.doi.org/10.1016/S2095-3119(12)60080-X

[75] J. Vandesompele, K. De Preter, F. Pattyn, B. Poppe, N. Van Roy, A. De Paepe and F. Speleman, “Accurate Normalization of Real-Time Quantitative RT-PCR Data by Geometric Averaging of Multiple Internal Control Genes," Genome Biology, Vol. 3, No. 7, 2002, pp. 1-12. http://dx.doi.org/10.1186/gb-2002-3-7-research0034

[76] S. Artico, S. Nardeli, O. Brilhante, M. Grossi-de-Sa and M. Alves-Ferreira, "Identification and Evaluation of New Reference Genes in Gossypium hirsutum for Accurate Normalization of Real-Time Quantitative RT-PCR Data,” BMC Plant Biology, Vol. 10, 2010, p. 49. http://dx.doi.org/10.1186/1471-2229-10-49

[77] N. A. Eckardt, "Abscisic Acid Biosynthesis Gene Underscores the Complexity of Sugar, Stress, and Hormone In- teractions,” Plant Cell, Vol. 14, No. 11, 2002, pp. 26452649. http://dx.doi.org/10.1105/tpc.141110

[78] Y. Osakabe, K. Maruyama, M. Seki, M. Satou, K. Shinozaki and K. Yamaguchi Shinozaki, "Leucine-Rich Repeat Receptor-Like Kinase1 Is a Key Membrane-Bound Regulator of Abscisic Acid Early Signaling in Arabidopsis,” Plant Cell, Vol. 17, No. 4, 2005, pp. 1105-1119. http://dx.doi.org/10.1105/tpc.104.027474

[79] F. Mantiri, S. Kurdyukov, S. Chen, and R. Rose, “The Transcription Factor MtSERF1 may Function as a Nexus between Stress and Development in Somatic Embryogenesis in Medicago truncatula," Plant Signaling and Behavior, Vol. 3, No. 7, 2008, pp. 498-500. http://dx.doi.org/10.4161/psb.3.7.6049

[80] Q. Zheng, Y. Zheng and S. Perry, “AGAMOUS-Like15 Promotes Somatic Embryogenesis in Arabidopsis and Soybean in Part by the Control of Ethylene Biosynthesis and Response,” Plant Physiology, Vol. 161, No. 4, 2013, pp. 2113-2127. http://dx.doi.org/10.1104/pp.113.216275

[81] S. Baudino, R. Brettschneider, V. Hecht, T. Dresselhaus, H. Lorz, C. Dumas and P. Rogowsky, "Molecular Characterization of Novel Maize LRR Receptor-Like Kinases, Which Belong to the SERK Family,” Planta, Vol. 213, No. 1, 2001, pp. 1-10. http://dx.doi.org/10.1007/s004250000471

[82] A. R. Paolacci, O. A. Tanzarella, E. Porceddu and M. Ciaffi, "Identification and Validation of Reference Genes for Quantitative RT-PCR Normalization in Wheat,” BMC Molecular Biology, Vol. 10, 2009, p. 11. http://dx.doi.org/10.1186/1471-2199-10-11

[83] K. Apel and H. Hirt, "Reactive Oxygen Species: Metabolism, Oxidative Stress, and Signal Transduction,” Annual Review of Plant Biology, Vol. 55, 2004, pp. 373-399. http://dx.doi.org/10.1146/annurev.arplant.55.031903.1417 $\underline{01}$

[84] C. Bowler, M. V. Montagu and D. Inze, "Superoxide Dismutase and Stress Tolerance," Annual Review of Plant Physiology and Plant Molecular Biology, Vol. 43, 1992, pp. 83-116.

http://dx.doi.org/10.1146/annurev.pp.43.060192.000503

[85] H. Willekens, S. Chamnongpol, M. Davey, M. Schraudner, C. Langebartels, M. V. Montagu, D. Inze and W. V. Camp, "Catalase Is a Sink for $\mathrm{H}_{2} \mathrm{O}_{2}$ and Is Indispensable for Stress Defence in C3 Plants,” EMBO Journal, Vol. 16, No. 16, 1997, pp. 4806-4816. http://dx.doi.org/10.1093/emboj/16.16.4806

[86] G. Noctor and C. Foyer, “Ascorbate and Glutathione: Keeping Active Oxygen under Control,” Annual Review of Plant Physiology and Plant Molecular Biology, Vol. 49, 1998, pp. 249-279.

http://dx.doi.org/10.1146/annurev.arplant.49.1.249

[87] R. Galland, B. Randoux, J. Vasseur and J. Hilbert, "Glutathione $S$-Transferase cDNA Identified by mRNA Differential Display Is Upregulated during Somatic Embryogenesis in Cichorium," Biochimica et Biophysica Acta, Vol. 1522, No. 3, 2001, pp. 212-216. http://dx.doi.org/10.1016/S0167-4781(01)00314-1

[88] F. Thibaud-Nissen, R. Shealy, A. Khanna and L. Vodkin, 
“Clustering of Microarray Data Reveals Transcript Patterns Associated with Somatic Embryogenesis in Soybean," Plant Physiology, Vol. 132, No. 1, 2003, pp. 118-136. http://dx.doi.org/10.1104/pp.103.019968

[89] K. R. Cui, G. S. Xing, X. M. Liu, G. M. Xing and Y. F.
Wang, "Effect of Hydrogen Peroxide on Somatic Embryogenesis of Lycium barbarum L.," Plant Science, Vol. 146, No. 1, 1999, pp. 9-16.

http://dx.doi.org/10.1016/S0168-9452(99)00087-4 
Appendix

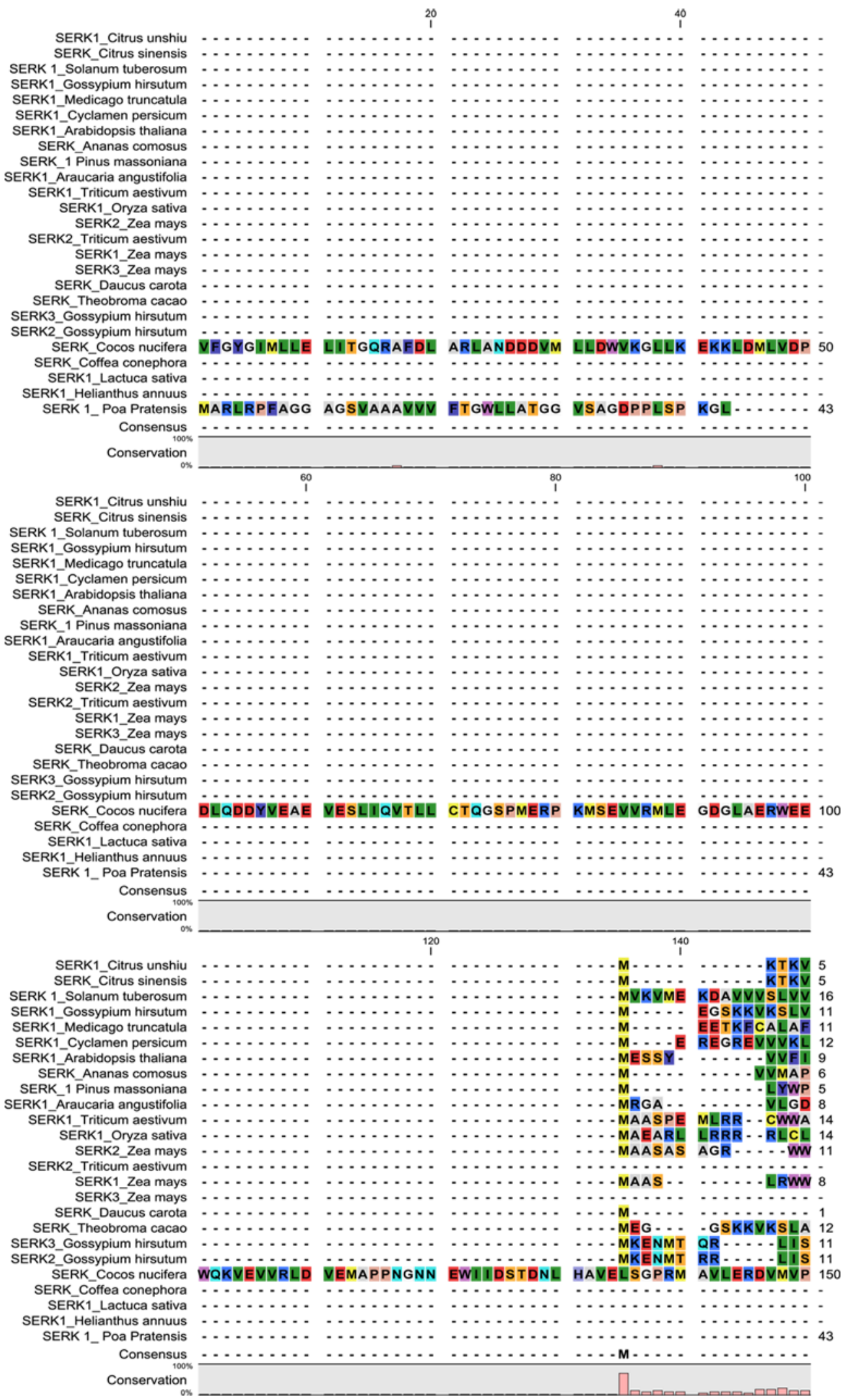




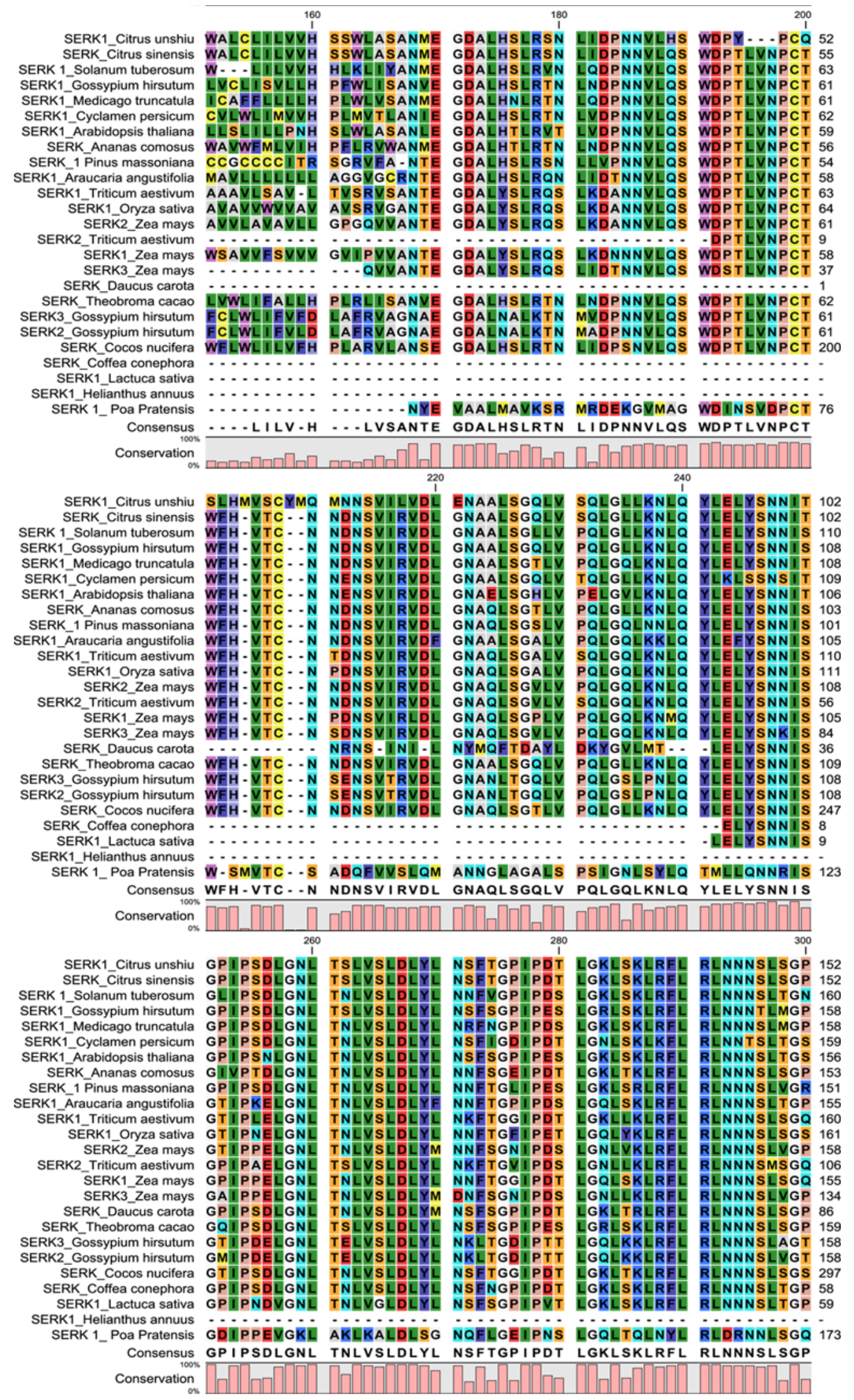

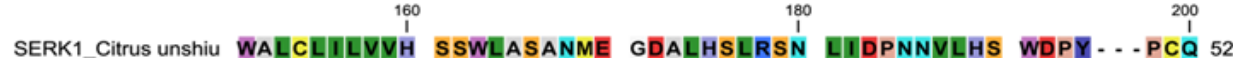
作 RK1-Arabidopsis thaliana LLSLILLPNH SLWLASANLE GDALHTLRVT LVDPNNVLQS WDPTLVNPCT 59 TO IERTAGAE GDALNALKTN MVDPNNVLOS WDPTLVNPCT 61

SERK1 Citrus unshiu SLHMVSCYMQ MNNSVILVDL ENAALSGQLV SQLGLLKNLQ YLELYSNNIT 102 GNAALSGL PQLGLLKLL - NENSVIRYD GNAELSGHLV PELGVLKNLQ YLELYSNNIT 106 T. RK1 Áraucaria angustifolia WFH - VTC - - N NDNSVIRVDF GNAALSGALV PQLGQLKKLQ YLEFYSNNIS 10 1_Triticum aestivum WFH-VTC - - N TDNSVIRVDL GNAQLSGALY SQLGQLKNLQ YLELYSNNIS 110

WFH - VTC- $N$ NDNSVIR

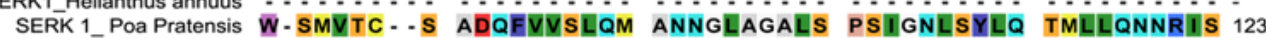
Consensus WFH-VTC.-N NDNSVIRVDL GNAQLSGQLV PQLGQLKNLQ YLELYSNNIS 2600300

SERK1 Citrus unshiu GPIPSDLGND TSLVSLDLYL NSFTGPIPDT EGKLSKLREL RENNNSLSGP 152 TPIPSD TNLVSLPLVL NRFNGPIPDS LGKLSKLRFL RLNNNSIMGP 158 GERK1_Cyclamen persicum GPIPSDLGNL TNLVSLDLYL NSFIGDIPDT LGNLSKLKFL RLNNTSLTGS 159 RK1_Arabidopsis thaliana GPIPSNLGNL TNLVSLDLYL NSFSGPIPES LGKLSKLRFL RLNNNSLTGS 156 作 SERK2 Zea mays GTIPPELGNL TNLVSLDLYM NNFSGNIPDS ENLVKLRFL RLNNNSLVGP 158 TSLVSLDLVI NKFTGVIPDS LGNLLKLRFL RLNNNSMSGQ 106 SERK3_Zea mays GAIPPELGNL TNLVSLDLYM NNFTGGIPDT LGQLSKLRFL RLNNNSLSGQ 155

SERK Daucus carota GPIPSDLGNL TNLVSLDLYM NSFSGPIPDT EGKLTRLRFI RLNNNSLSGP 86 TSLVLDLYL NSFSGPIPES LGRLSKLRFI RINNNSLSGP 159

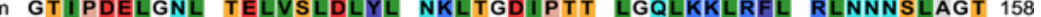
2_Gossypium hirsutum GMIPDELGNL TELVSLDLYL NKLTGDIPTT LGQLKKLRFL RLNNNSLVGT 158 SERK_Cocos nucifera GTIPSDLGNL TNLVSLDLYL NSFTGGIPDT LGKLTKLRFL RLNNNSLSGS 297 SERK1_Lactuca sativa GPIPNDVGNL TNLVGLDLYL NSFSGPIPVT LGKLSKLRFL RLNNNSLTGP 59

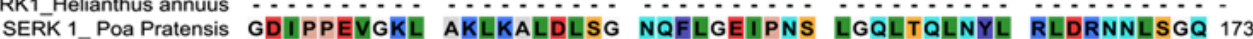

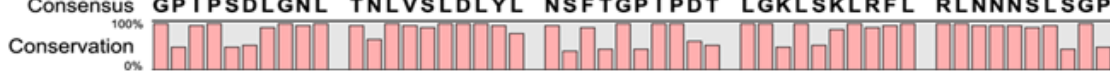




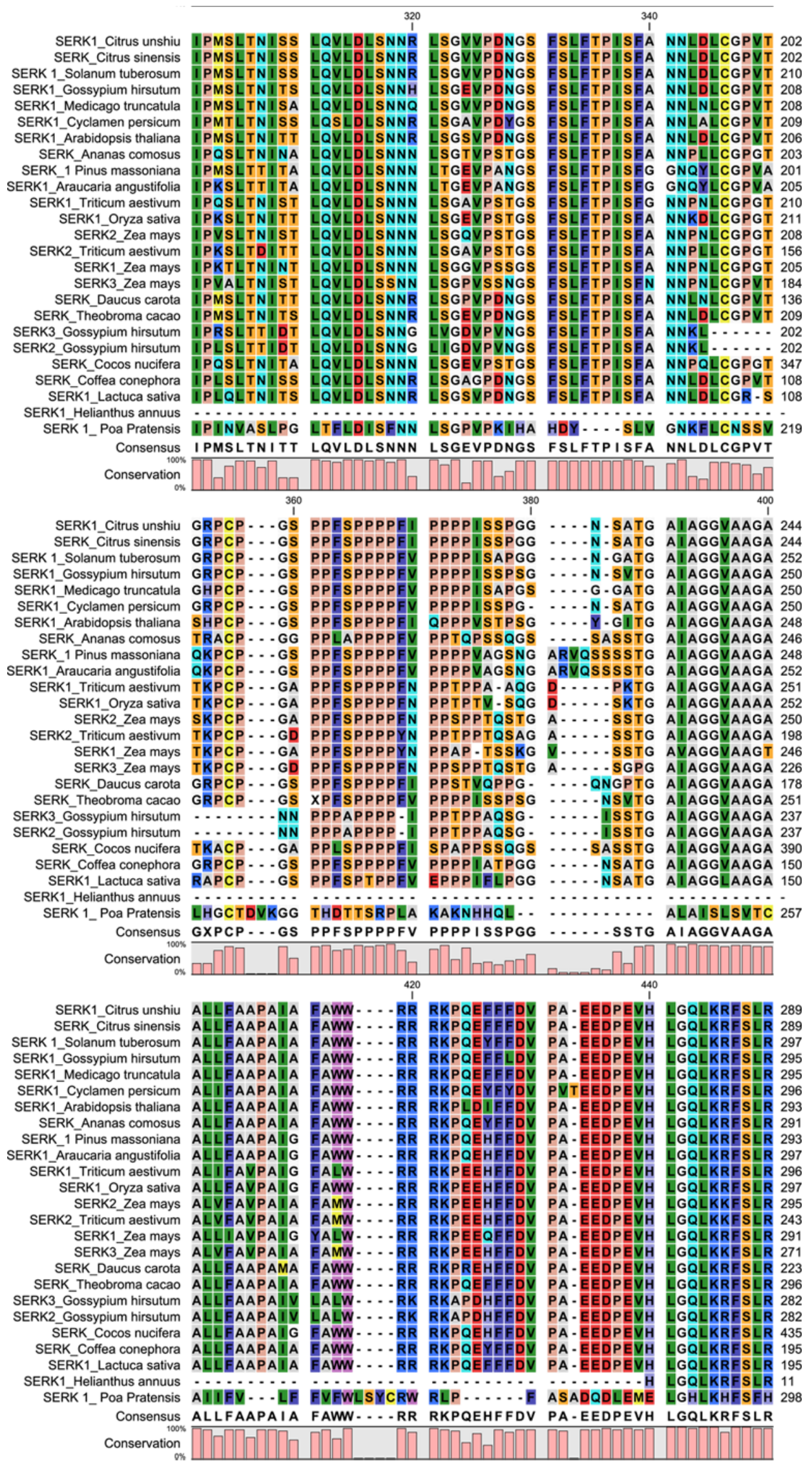




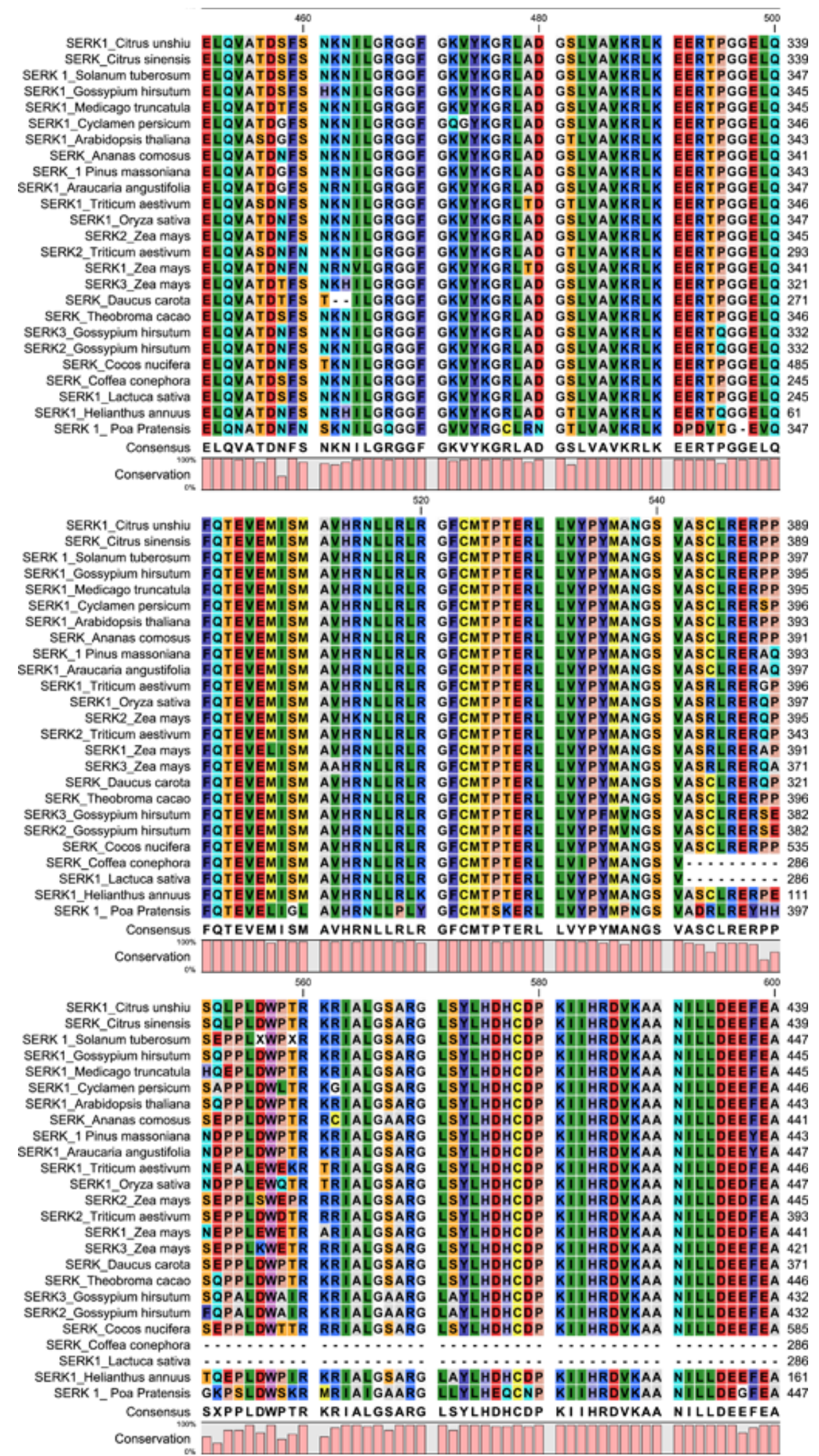


SERK1 Citrus unshiu VVGDFGIAKI MDYKDTHVT⿱

SERK Citrus sinensis VVGDFGLAKL MDYKDTHVTT AVRGTIGHIA PEYLSTGKSS EKTDVFGYGI 489 SERK 1 Solanum tuberosum VVGDFGLAKL MDYKDTHVTT AVRGTIGHIA PEYLSTGKSS EKTDVFGYGI 497 SERK1_Gossypium hirsutum VVGDFGLAKL MDYKDTHVTT AVRGTIGHIA PEYLSTGKSS EKTDVFGYGI 495 SERK1_Medicago truncatula VVGDFGLAKL MDYKDTHVTT AVRGTIGHIA PEYLSTGKSS EKTDVFGYGI 495 SERK1_Cyclamen persicum VVGGEGLAKL MDYKDTHVTT AVRGTIGHIA PEYLSTGKSS EKTDVFGYGI 496 SERK1_Arabidopsis thaliana VVGDFGLAKL MDYKDTHVTT AVRGTIGHIA PEYLSTGKSS EKTDVFGYGI 493 SERK Ananas comosus VVGDFGLAKL MDYKDTHVTT AVRGTIGHIA PEYLSTGKSS EKTDVFGYGII 491 SERK 1 Pinus massoniana VVGDFGLAKL MDYKDTHVTT AVRGTIGHIA PEYLSTGKSS EKTDVFGYYI 493

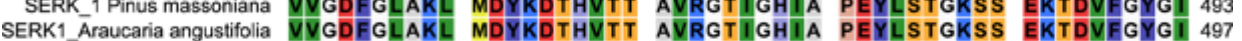
SERK1_Araucaria angustifolia VVGDEGLAKL MDYKDTHVTT AVRGTIGHIA PEYLSTGKSS EKTDVVGYGI 497
SERK1_Triticum aestivum VVGDFGLAKL MDYKDTHVTT AVRGTIGHIA PEYLSTGKSS EKTDVFGYGI 496 SERK1_Oryza sativa VUGDEGLAKL MDYKDTHVTT AVRGTIGHIA PEYLSTGESS EKTDVFGYGI 497 SERǨ2_Zea mays VVGDFGLAKL MDYKDTHVTT AVRGTIGHIA PEYLSTGKSS EKTDVFGYGI 495 SERK2_Triticum aestivum VVGDFGLAKL MDYKDTHVTT AVRGTIGHIA PEYLSTGKSS EKTDVFGYGI 443 SERK1_Zea mays VVGDFGLAKL MDYKDTHVTT AVRGTIGHIA PEYLSTGKSS EKTDVFGYGI 491 SERK3_ZEa mays VVGDFGLAKL MDYKDTHVTT AVRGTIGHIA PEYLSTGKSS EKTDVFGYGI 471

SERK_Daucus carota VYGDFGLARL MDYKDTHVTT AVRGTLGYIA PEYLSTGKSS EKTDVFGYII 421

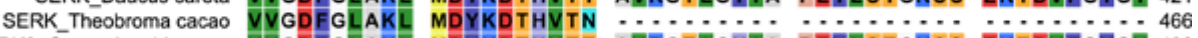
SERK3_Gossypium hirsutum VYGDFGLAKL MDYKDTHVTT AVRGTIGHIA PEYLSTGESS EKTDVFGYGV 482 SERK2_Gossypium hirsutum VVGDFGLAKL MDYKDTHVTT AVRGTIGHIA PEYLSTGKSS EKTDVSGMGV 482 SERK_Cocos nucifera VVGDEGLAKL MDYKDTHVTT AVRGTIGHIA PEYLSTGKSS EKTD..... 629

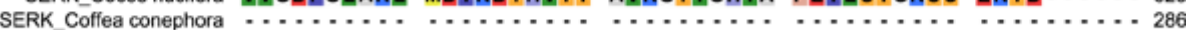

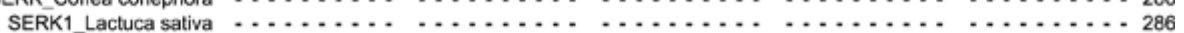

SERK1_Helianthus annuus VVGDFGLAKL MDYKDTHVTT AVRGTIGHIA PEYLSTGKSS EKTDVFGYGV 211 SERK 1_PoaPratensis VVGDFGLAKL EDRQDSHVTT AVRGTIGHIA PEYLSTGQSS EKTDVYGEGI 497 Consensus VVGDFGLAKL MDYKDTHVTT AVRGTIGHIA PEYLSTGKSS EKTDVFGYG

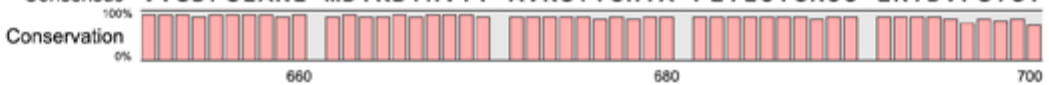

SERK1_Citrus unshiu MLLELITGQR AFDLARLAND DDVMLLDWVK GLLKEKKLEM EVDPDLONNY 539

SERK_Citrus sinensis MLLELI TGQR AFDLARLAND DDVMLLDWVK GLLKEKKLEM LVDPDLONNY 539 SERK 1_Solanum tuberosum MLLELI TGQR AFDLARLAND DDVMLLDWVK GLLKEKKLEM TVDPDLQNKY 547 SERK1_Gossypium hirsutum MLLELI TGQR AFDLARLAND DDVMLLDWVK GLLKEKKLEL CVDPDLQTNY 545 SERK1 Medicago truncatula MLLELITGQR AFDLARLAND DDVMLLDWVK GLLKEKKLEM LVDPDLKTNY 545 SERK1_Cyclamen persioum ME SERK1 C SERK_Ananas comosus MLLELI TGQR AFDLARLAND DDVMLLDWVK GLLKEKKLEM LVDPDLONNY 541 SERK_1 Pinus massoniana MLLELI TGQR AFDLARLAND DDVMLI DWVK GLLKERRLDM CVDPDLKNNY 543 SERK1_Araucaria angustifolia MLLELI TGQR AFDLARLAND DDVMLLDWVK GLLKERRLDM CVDPDLKNNY 547 SERK1_Triticum aestivum MLLELITGQR AFDLARLAND DDVMLLDWVK GLLKEKKVEM LVDPDLQSVY 546 SERK1_Oryza sativa MLLELITGQR AFDLARLAND DDVMLLDWVK GLLKEKKVEM LVDPDLQSGF 547 SERǨ2 Zea maYS MLLELI TGQR AFDLARLAND DDVMLLDWVK GLLKEKKVEM LVDPDLQKAYY 545

SERK2 Triticum aestivum TLLELI ITGQR AFDLARLAND DDVMLLDWVK GLKEKKVEM TVDPDLQSNY 493 SERK1_Zea mays MLLELITGQR AFDLARLAND DDVMLLDWVK ALLKEKKLEQ LYDPDLQGRY 541 SERK3_Zea mays MLLELI TGQR AFDLARLAND DDVMLLDWVK GLLKEKKVEM LUDPDLONAY 521

SERK_Daucus carota MLLELI IGQR AFDLARLAND DDVMLLDWVK SLLKEKKLEM LVDPDLENNY 471

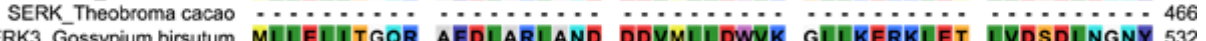
SERK2 Gossypium hirsutum MLLELI ITGR AEDLARLAND DDVMLLDWVK GLLKERKLET LVDSDLNGNY 532

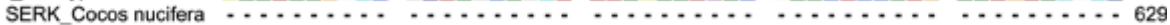

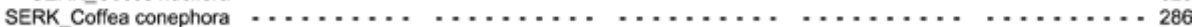

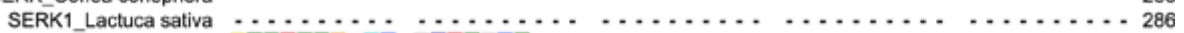

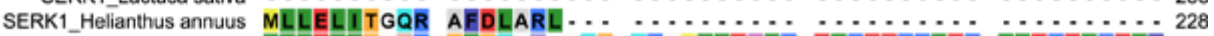
SERK 1_Poa Pratensis ELLELI ITGK TLSNGH-GQS QKGMILDWVR ELKEEKKLDK EVDRDLKDLF 546 Consensus MLLELITGQR AFDLARLAND DDVMLLDWVK GLLKEKKLEM LVDPDLQNNY

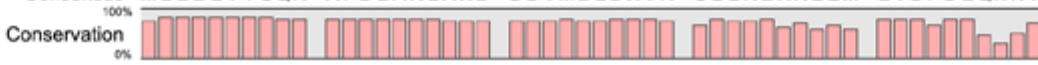

SERK1_Citrus unshiu VEAEVEQLIQ VALLCTQGSP MDRPKMSEVV RMLEGDGLAE RWDEWQKVEV 589 SERK_Citrus sinensis VEAEVEQLIQ VALLCTQGSP MDRPKMSEVV RMLEGDGLAE RWDEWQKVEV 589 SERK 1_Solanum tuberosum VEAEVEQLIQ VALLCTQSNP MDRPKMSEVV RMLEGDGLAE RWDEWOKVEV 597 SERK1_GOSSYPium hirsutum VETEVEOLIO VALETQSPP MDRPKMSEVV RME EGDGIAE RWDEWOKVEV 595 TERK1_Me IEAEVEQLIO VALLCTQGSP MDRPKMSDVV RMLEGDGLAE RWDEWQKGEV 595 SERK1_Cyclamen persicum VEPEVEQLIQ VALLCTQGSP VDRPKMSEVV RMLRGDGLAE KWDEWQKVEV 596 SERK1_Arabidopsis thaliana EERELEQVIQ VALLCTQGSP MERPKMSEVV RMLEGDGLAE KWDEWQKVEI 593

SERK_Ananas comosus IESEVESLIQ VALLCTQGSP MERPKMSEVV RMLEGDGLAE RWEEWQRVEV 591 SERK_1 Pinus massoniana VEAEVEQLIO VALLCTQGSP MDRPKMSEVV RMLEGDGLAE RWEEWQKVEV 593 SERK1_Araucaria angustifolia VEAEVEQLIO VALLCTQGSP MDRPKMSEVV RMLEGDGLAE RWEEWQKVEV 597 SERK1 Tritium aestiUm VEHEVEALIO VAL CTOGSP MDPPKMSEVV RMLEGDGLAE RWEEWOKVEV 506

SERK1_Oryza sativa VEHEVESLIQ VALLCTQGSP MDRPKMSEVV RMLEGDGLAE RWEEWQKVEV 597 SERK2 Zea mays EEVEVESLIO VALLCTQGSP MDRPKMSEVV RMLEGDGLAE RWEEWQKVEV 597 SERK2_Zea mays EEVEVESLIQ VALLCTQGSP LDRPKMSEVV RMLEGDGLAE RWDEWQKVEV 595
SERK2_Triticum aestivum EETEVESLIQ VALLCTQGSP VERPKMSEVV RMLEGDGLAE RWEEWQKVEV 543 SERK1_Zea mays VDQEVESLIQ VALLCTQGSP MERPKMSEVA RMLEGDGLAE RWEQWQKVEV 591

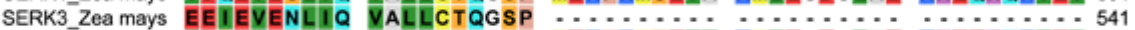

SERK_Daucus carota IDTEVEQLIQ VALLCTQGSP MERPKMSEVV RMLEGDGLAE KWDEWQKVEV 521

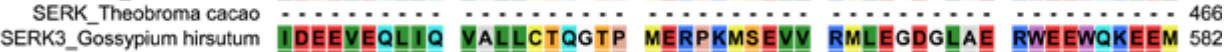

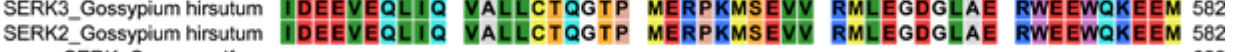

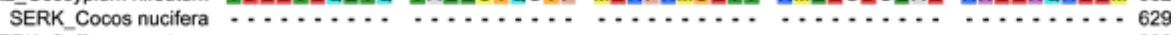

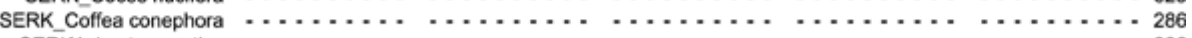

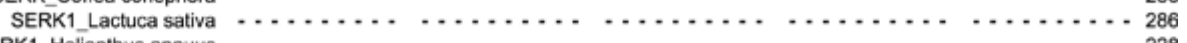

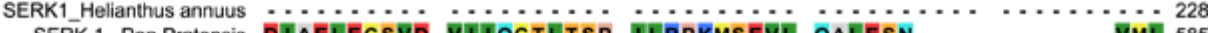
SERK 1_Poa Pratensis DIAEIEC SVD Consensus VEAEVEQL IQ VALLCTQGSP MDRPKMSEVV RMLEGDGLAE RWXEWQKVEV

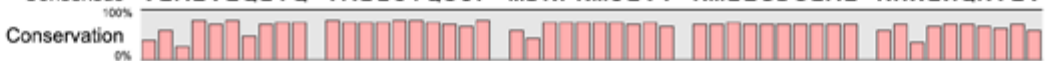




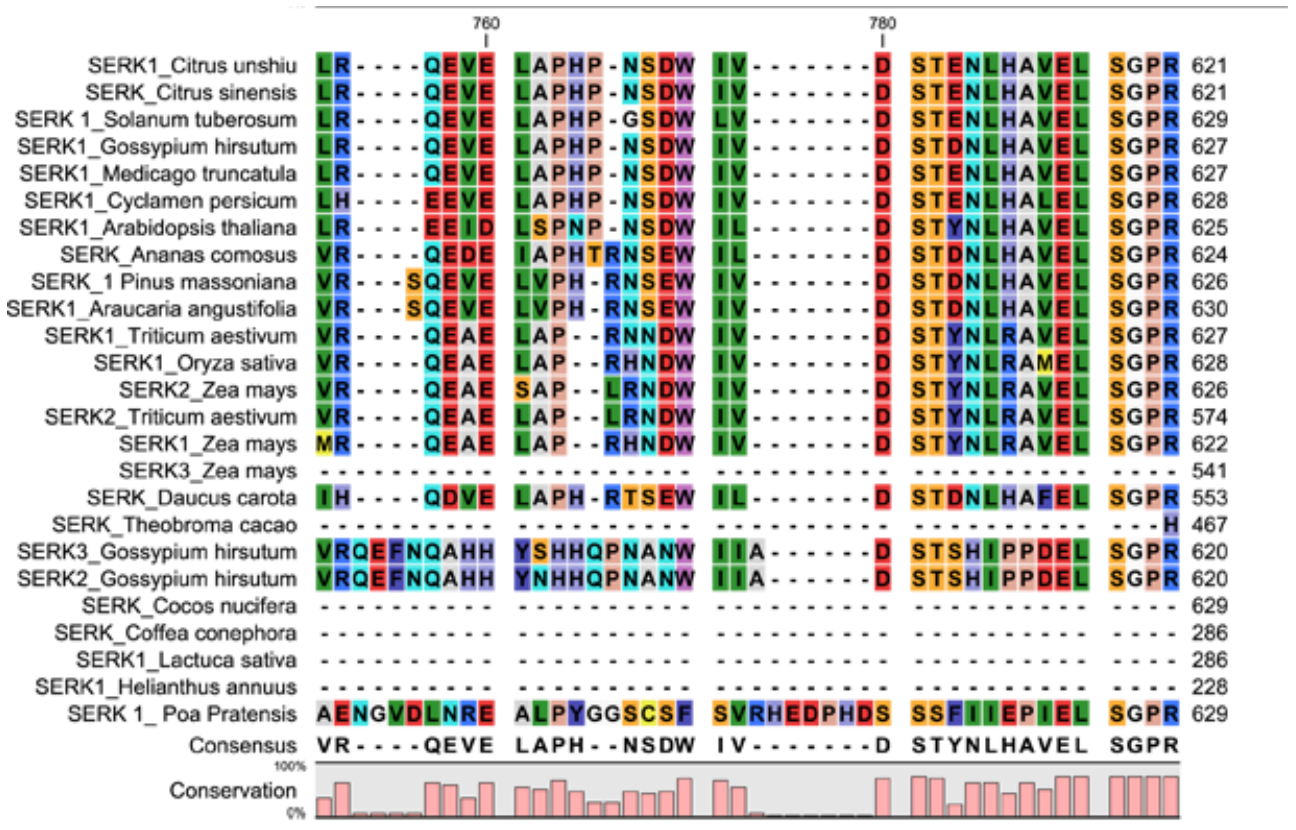

Figure S1. Multi-alignment of cotton SERK proteins showing the similarities with other species SERK protein variants. The amino acid sequence of dicot and monocot species exhibited high homologous regions mainly in the receptor kinase region, with maximum differences in their peptide signal domains.

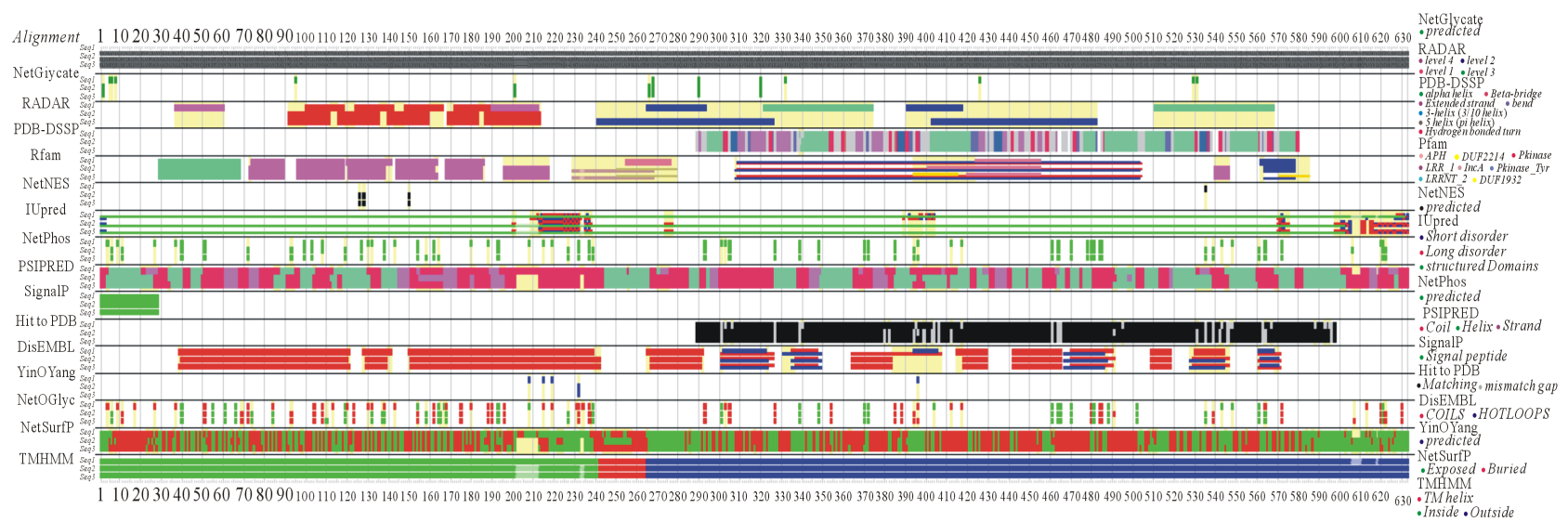

Figure S2. Analyses of functional domain differences in the protein sequences of three cotton SERK variants i.e. GhSERK1 (labelled as seq1), GhSERK2 (labelled as seq2) and GhSERK3 (labelled as seq3) to establish a relationship between the structural specificities evolved at N-terminal domain and the acquisition of SE. In GhSERK1 protein sequence, eight additional Glycation points were observed along with significant changes in the repeat pattern. Further, location of nuclear export signal in GhSERK1 was predicted between 530 - 540 amino acid while in GhSERK2 and GhSERK3 harbors between 120 - 150 amino acid. Wide variation in phosphorylation sites in GhSERK1 protein sequence was shown in comparison of its other variants. Predicted secondary structure has also variations along with difference in intrinsic protein disorder in GhSERK1 from GhSERK2 and GhSERK3. There are four O-glyc sites in GhSERK1 whereas only one in each of GhSERK2 and GhSERK3 and the positional variation of this site was also predicted. 